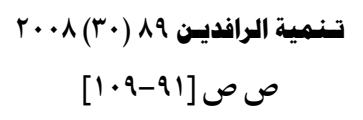

$$
\begin{aligned}
& \text { اعتماد بعض المداخل الإدارية لمواجهة مقاومة التغييز } \\
& \text { "در اسة حالة"الي" } \\
& \text { الاكتور محمد مصطفى القصيمي } \\
& \text { مدرس - قسم نظم المعلومات الإدارية } \\
& \text { كلية الإدارة و الاقتصناد - جامعة الموصل الإريل }
\end{aligned}
$$

\footnotetext{
المستخلص

تسعى الار اسة الحالية إلى تسليط الضوء على ظاهرة مقاومة التغيير التي تعد إحدى الظواهر

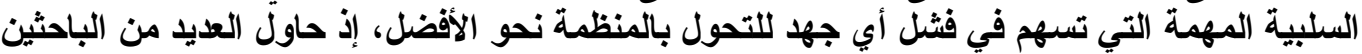

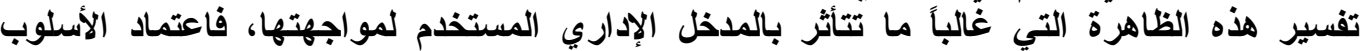

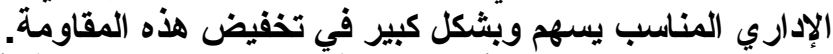

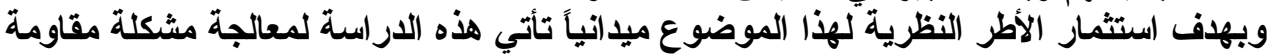
التغيير في الثركة العامة لصناعة الألبسة الجاهزة في الموصل وتوجيه جهود الإدارة مئه لاختيار المدخل

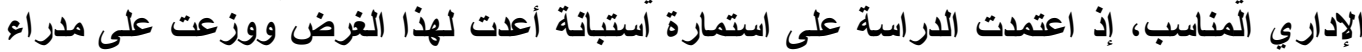

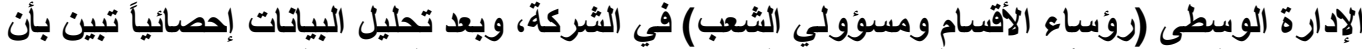

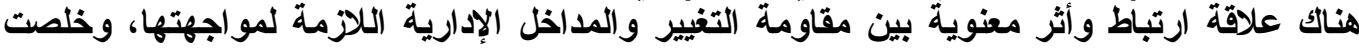

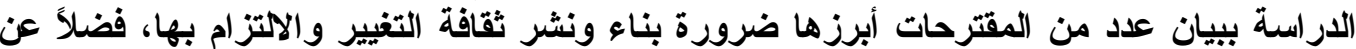
مشاركة العاملين في صنع قرارات التغيير وبما يخدم مصلحة فئرة الثركة.
}

\title{
Dependence of Some Administrative Approaches to Encounter Resistance of Change A Case Study
}

Mohammed M. Al-Kusaimy (PhD)

Lecturer

Department of Management Information Systems

University of Mosul

\begin{abstract}
The current study tries to shed light on the phenomenon of change resistance, which is considered one of potential negative phenomena that may be attributed to the failure of any effort exerted to develop the organization. Many researchers tried to explain this phenomenon that may be affected by the administrative approach used to encounter it. Adopting suitable administrative technique perhaps contribute a considerable extent in decreasing such resistance.

To invest the theoretical frameworks of this subject in the fields, this study deals with the problem of change resistance in the General Company for Ready - Made Clothes Industry in
\end{abstract}

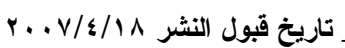$$
\text { تاريخ التسلم }
$$ 
Mosul City and guides the administration's efforts to choose the suitable administrative approach. The current study adopted a questionnaire prepared for this target and distributed among managers of intermediate administration in the company. Analyzing the data statistically, it became obvious that there is a significant correlation between the change resistance and the administrative techniques required to encounter it. The study showed some suggestions. The most distinct one is the necessity of establishing and spreading education of change as well as participating administrators in change the decisions - making for the interest of company.

المقدمة

يحظى موضوع التغيير باهتمام منز ايد في المنظمات كافة، ويزداد هذا الاهتمام

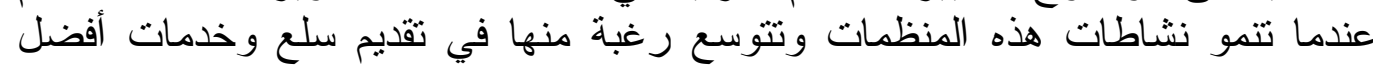

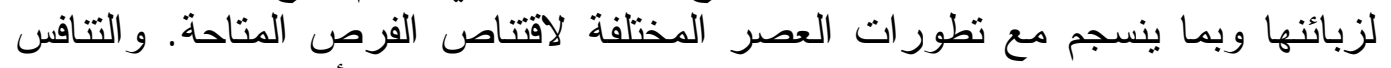

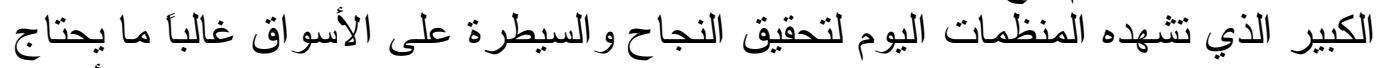

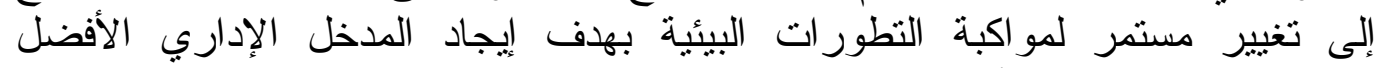

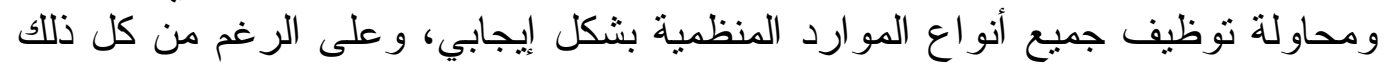

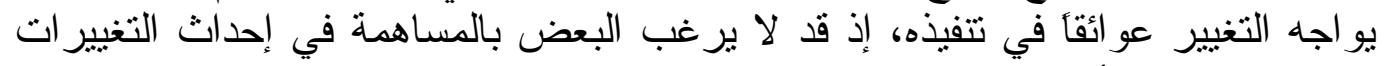

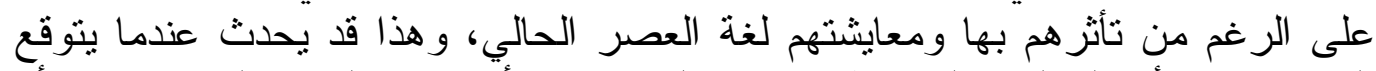

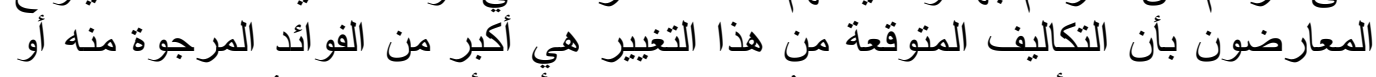

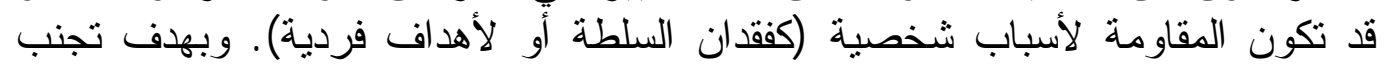

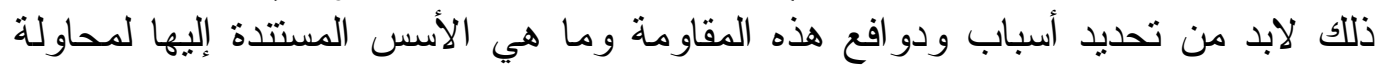
مو اجهة ذلك.

وتشكل مقاومة التغيير إحدى المشاكل الجوهرية التي تواجه عملية اندماج معدل

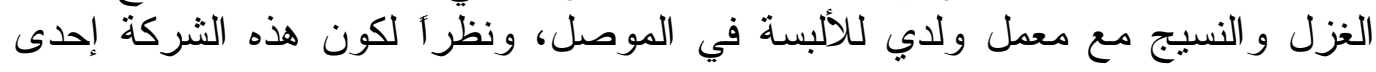

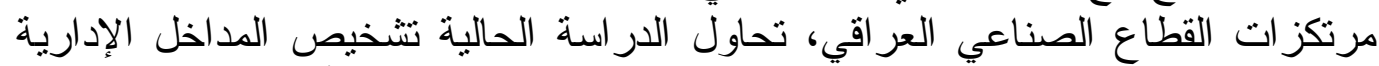

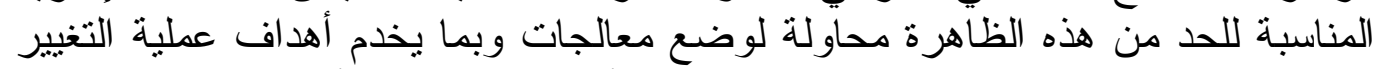

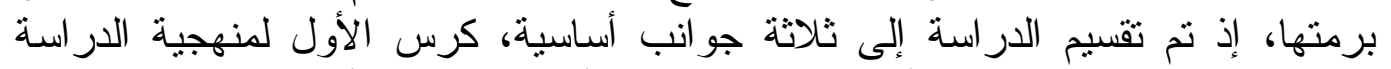

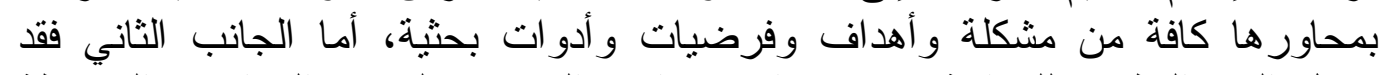
تتاول البعد النظري للار اسة وتضمن الاستعر اض المرجعي لبعض الدار الدار اسات المرتبطة

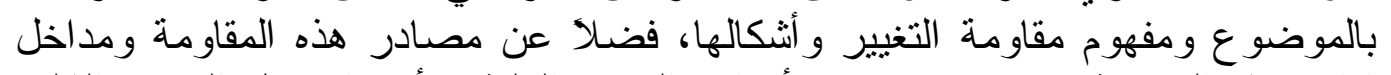

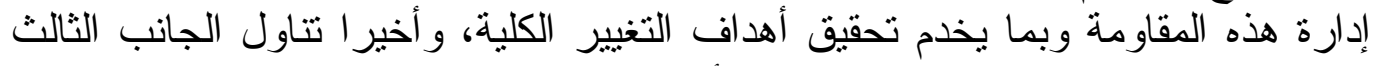

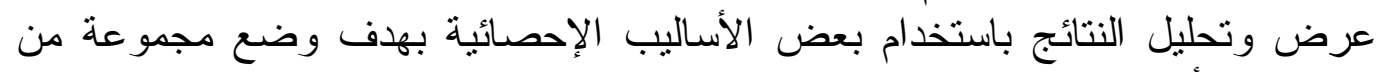
المقترحات أمام المعنيين في إدارة الثتئج الثركة.

\section{1 \\ ا 1 - 1 مشكلة الإطار المنهية}

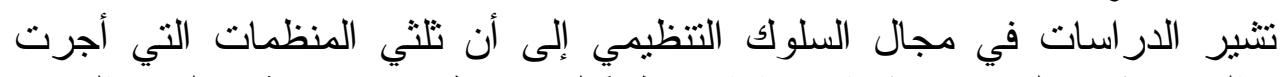

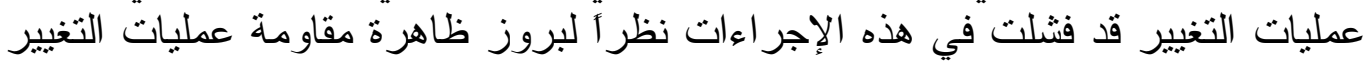

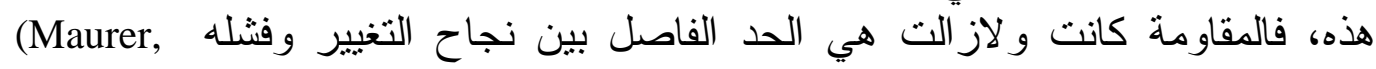




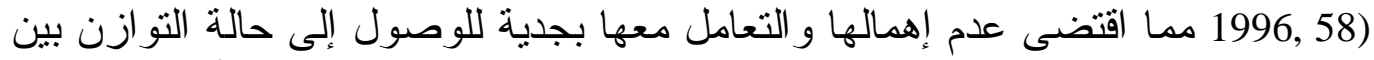
التغيير و استجابة العاملين له ميدانياً ونظر آ للتغيير الحاصل فئل في معمل الألبسة الجاهزة

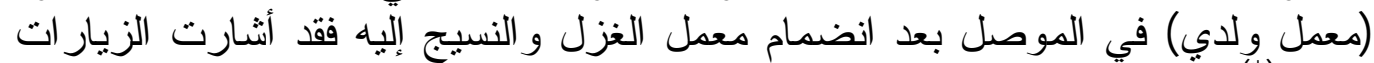

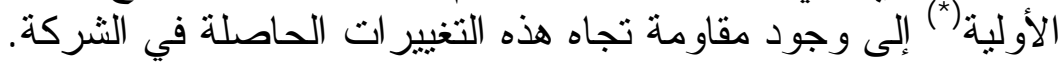

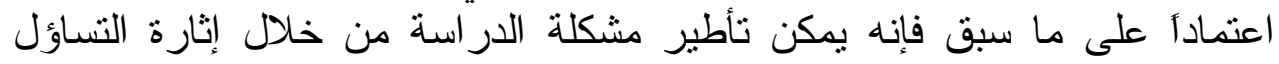

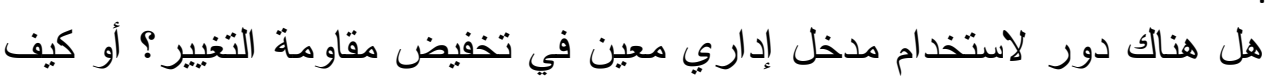
يمكن استخدام بعض المداخل الإدارية في مو اجهة مقاومة لإنة التغيير؟ r - 1 أهداف الار استة انطلاقا من المشكلة المذكورة آنفاً فإن هدف الدةر اسة يتمثل بالآتي:

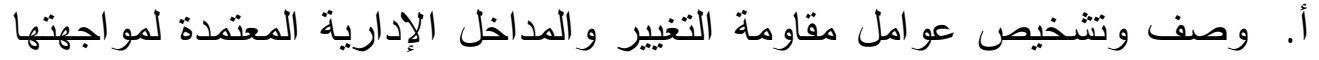
في الثركة المبحوثة. ب. در اسة الطبيعة المتداخلة لعلاقات الارتباط والأثز بين أنثكال مقاومة التغيير

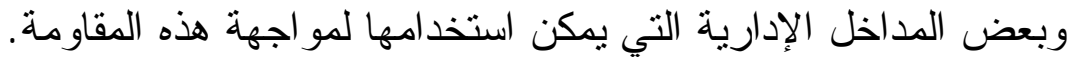

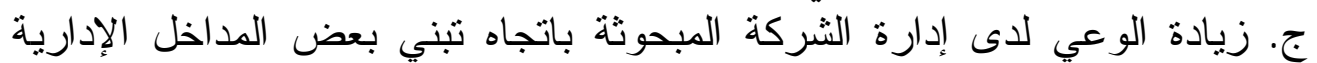
ألتي تتتاسب وتخفيض مقاومة التخبي التغيير . ب - أنموذّج الار اسة وفرضياتها تتطلب المعالجة المنهجية لمشكلة الدر اسة بندة بناء أنموذج الفتر اضي يعبر عن العلاقة المنطقية بين متغير ات الدر اسة من خلال المخطط الآتي:

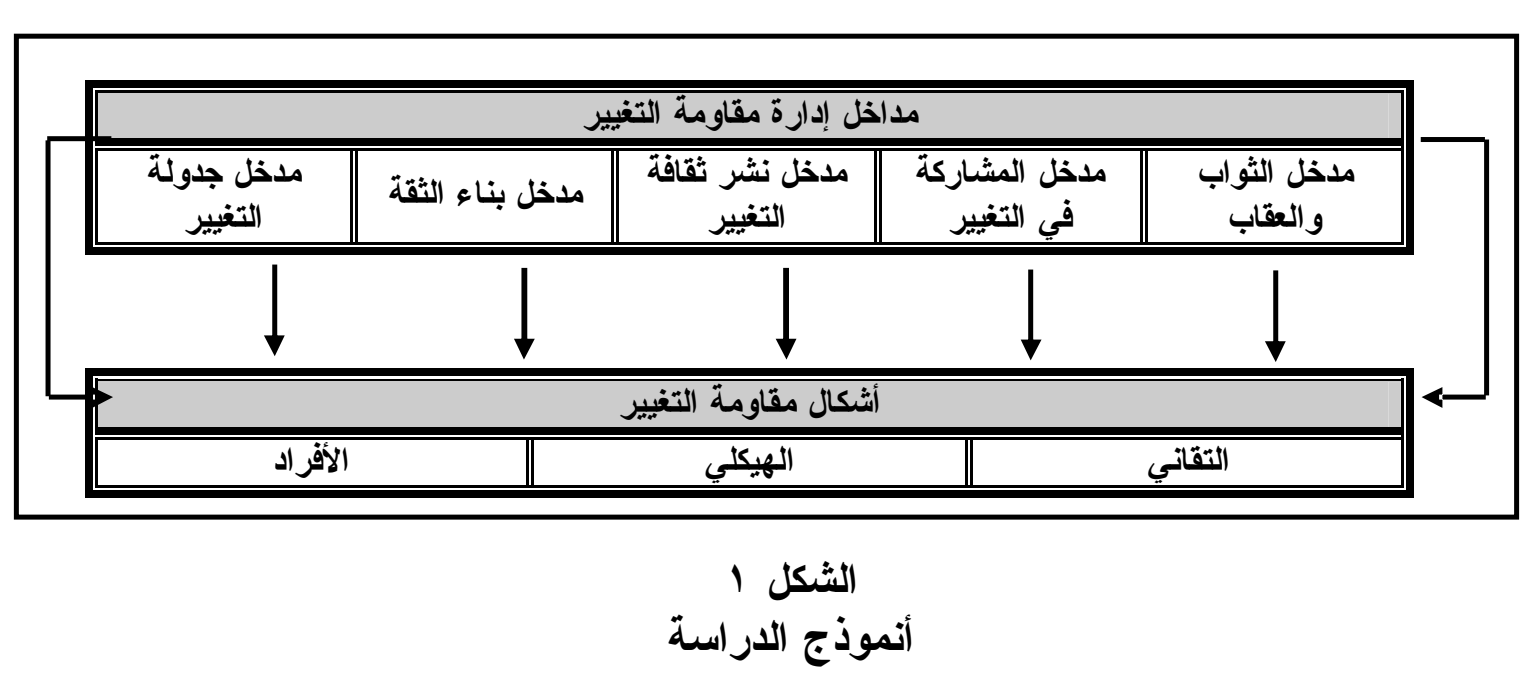

وتبرز أسباب صياغة أنموذج الدراسة كما هو موضح في الآتي:

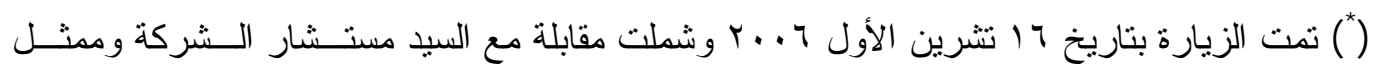
وزارة الصناعة في مجلس الإدارة. 
1. تعبّر المتغير ات التي تضمنها الأنموذج عن آر اء اغلب الباحثثن و المتخصصين

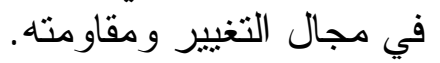

r. إمكانية قياس المتغير ات الواردة في الأنموذج المذكور آنفأ.

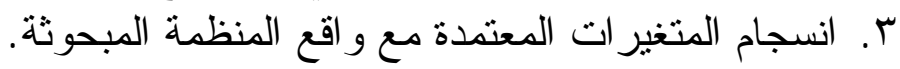

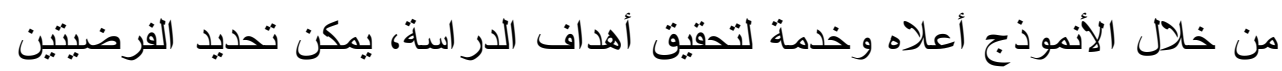

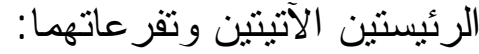

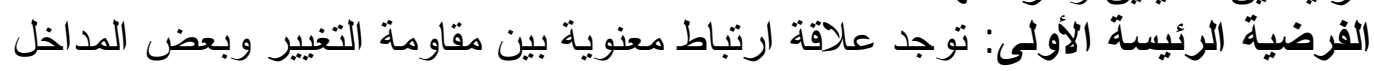

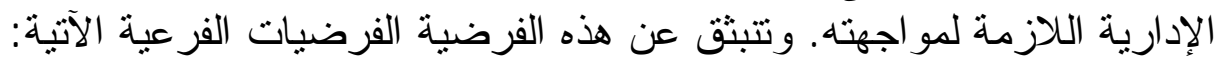

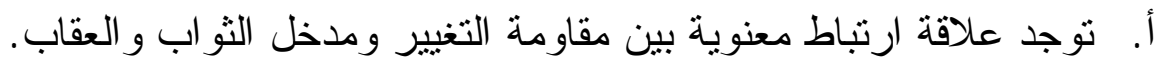

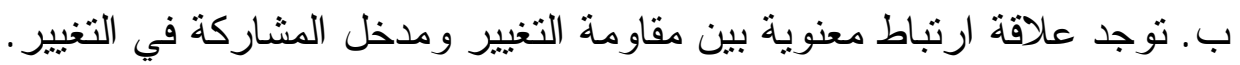

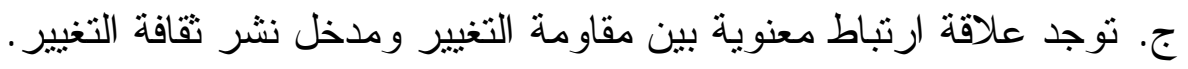

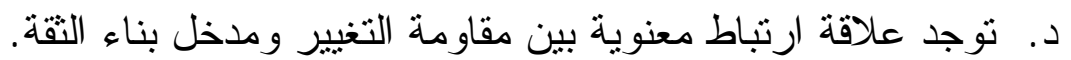

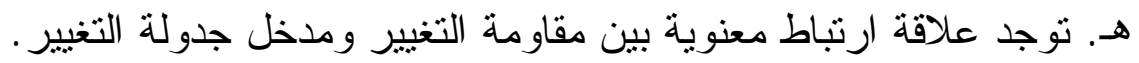

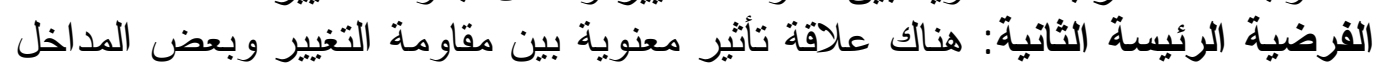

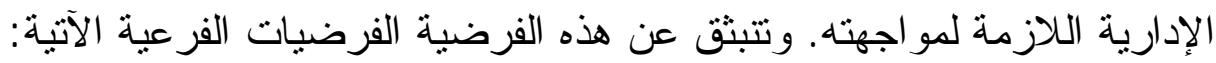

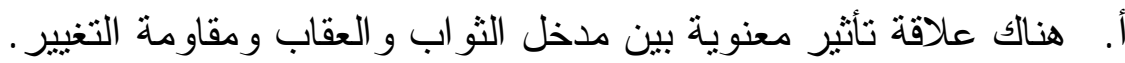

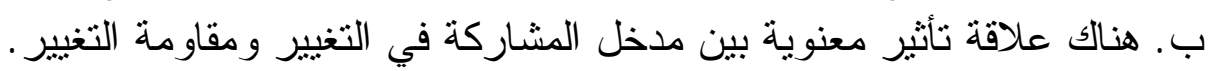

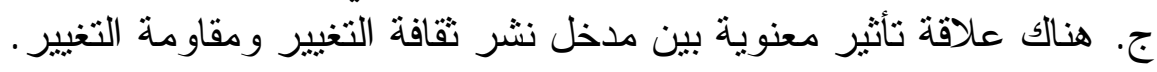

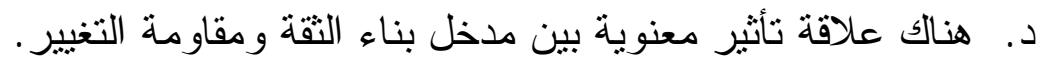

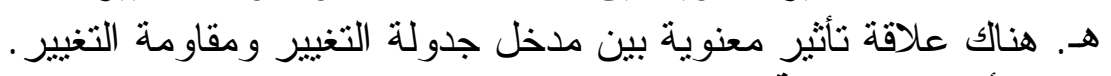

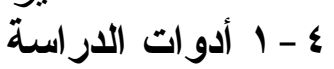

$$
\text { لاختبار فرضيات الدر اسة الرئيسة و الفر عية تم اعتماد الآتي: }
$$

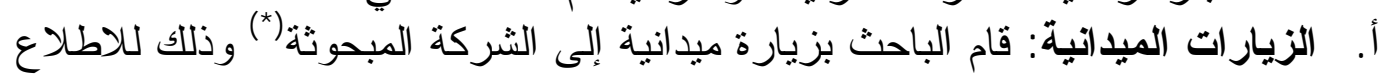

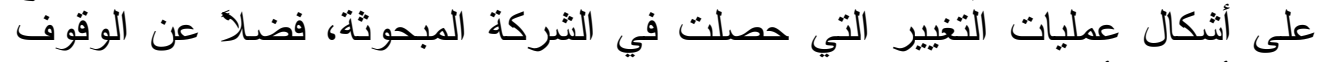
على أبرز الأسباب الظاهرة للقاومة التغيير و المداخل الإدارية التي تعتمدها إدارة التهارة

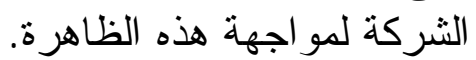

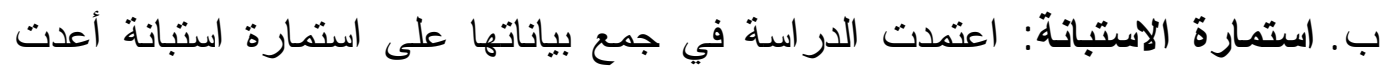

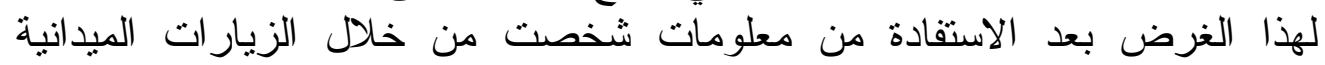

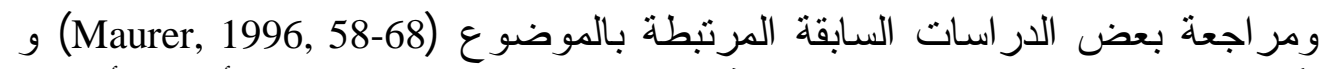

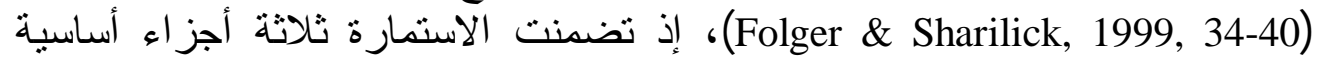

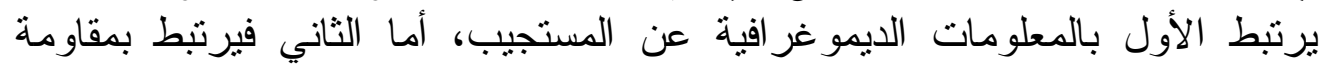
التغيير من خلال أنثكال هذه المقاومة، في حين يقيس الجزء الثئ الثالث المداخل الإدارية

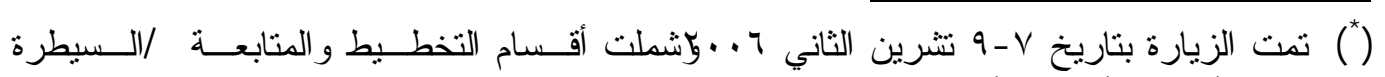

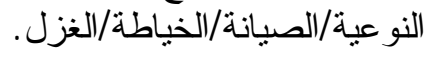


المعتمدة من قبل الثركة المبحوثة في مو اجهة مقاومة التغيير ـ وقد تم اعتماد المقياس

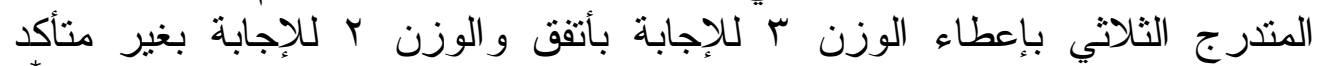

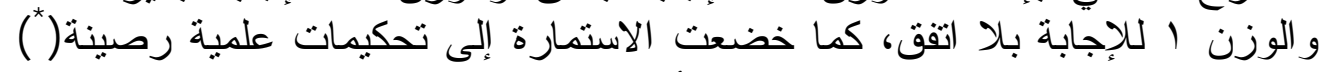

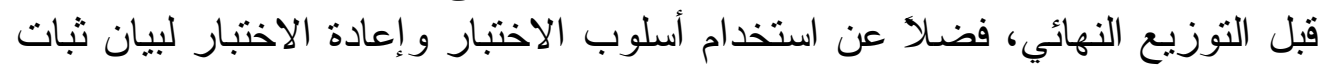

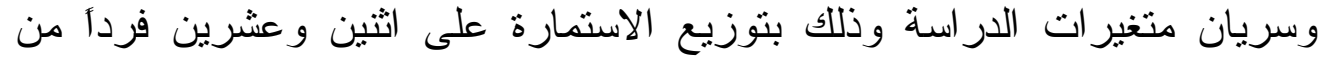

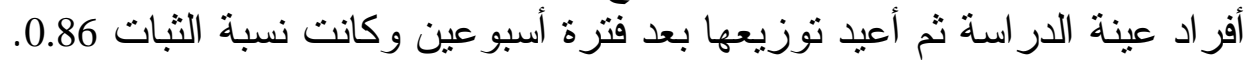

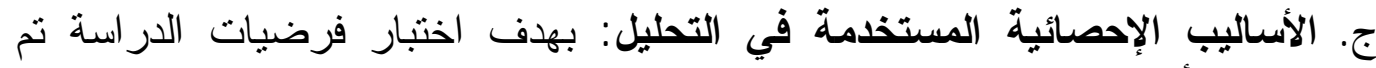

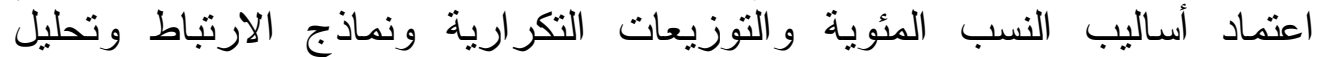

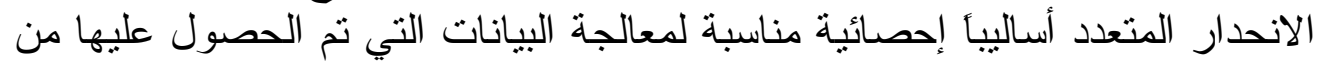

خلال استمارة الاستبانة وبالاعتماد على البرمجية الجاهزة Minitab.

\section{- 1 تركية عينة الدر استة}

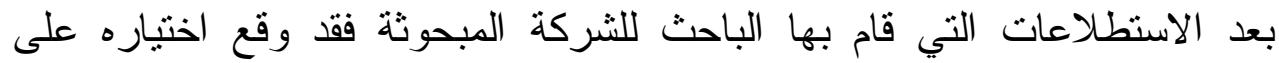

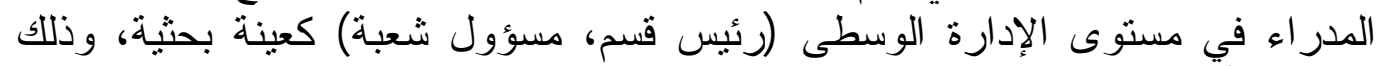

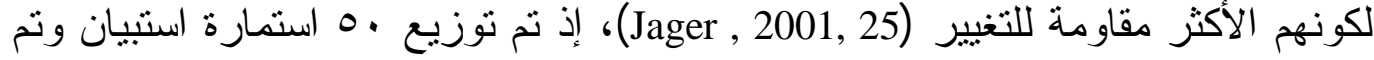

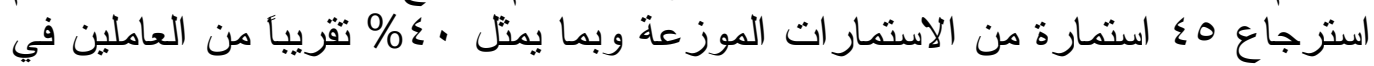

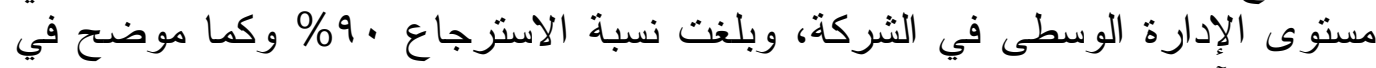

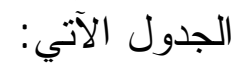

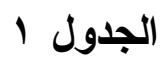

الاستمار ات الموزعة و المسترجعة بحسب الموقع الوظيفي

\begin{tabular}{|c|c|c|}
\hline مسؤول شعبة & رئيس قسم & اسم المعمل التابع للثشركة:الموقع الوظيفي \\
\hline$\varepsilon$ & 11 & معمل الغزل و النسيج \\
\hline$\Lambda$ & 10 & معمل ولدي \\
\hline$\Gamma$ & $\varepsilon$ & معمل القطن الطبي \\
\hline $\bar{r}$ & $\bar{r}$ & محلج قطن كركوك \\
\hline IV & ru & مجموع الاستمار ات الموزعة \\
\hline 17 & rq & مجموع الاستمار ات المسترجعة \\
\hline
\end{tabular}

(*) د. محفوظ حمدون الصو اف / أستاذ مساعد / كلية الإدارة و الاقتصاد / جامعة الموصل.

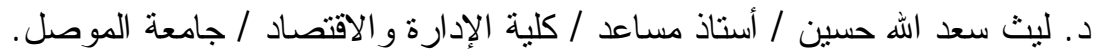

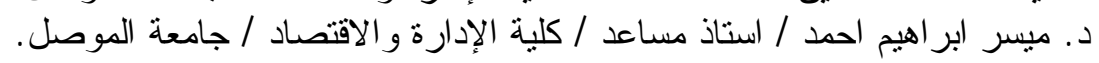




\section{r بـ البُعد النظري للادراسة

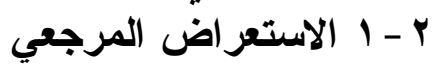

تزصينا للجانب النظري يرى الأني الباحث ضرورة عرض بعض الدر اسات المرتبطة

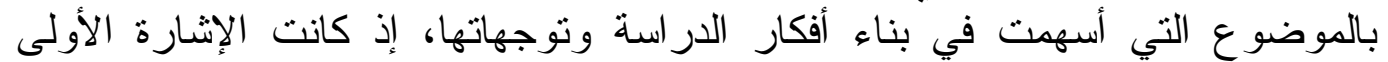

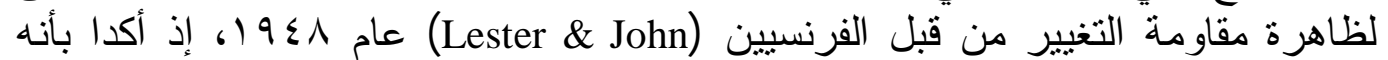

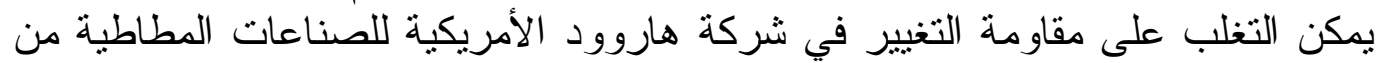

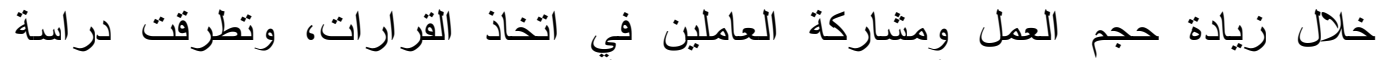
(Kanter)

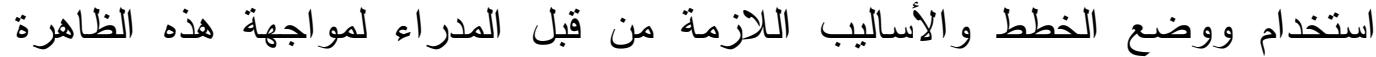

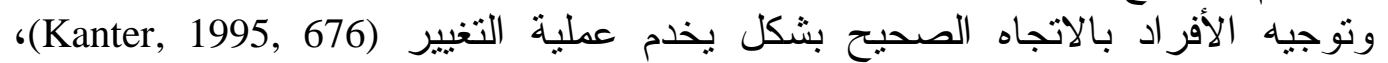
وتتاول الباحثنان (White \& Bednar) من خلاهل در اسة أجرياها أعر اض ظاهية الاهرة مقاومة

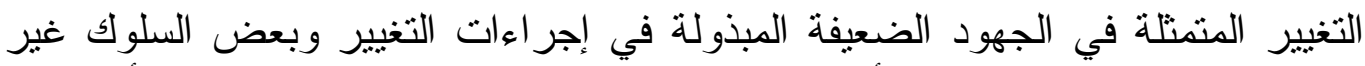

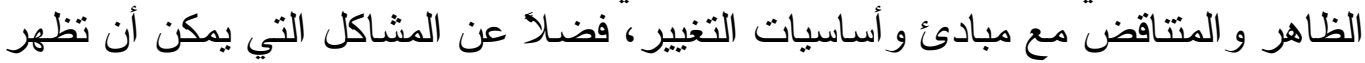

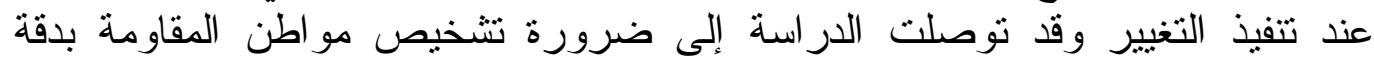

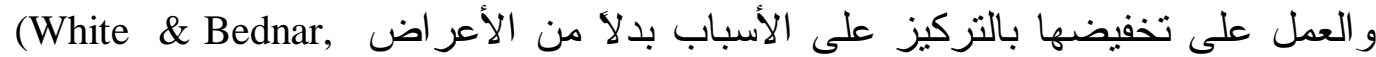

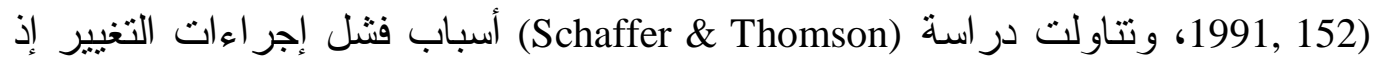

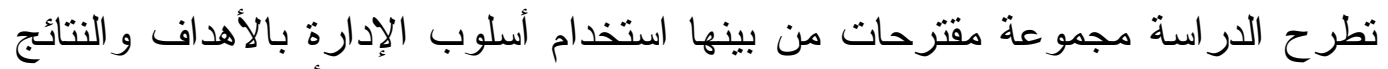

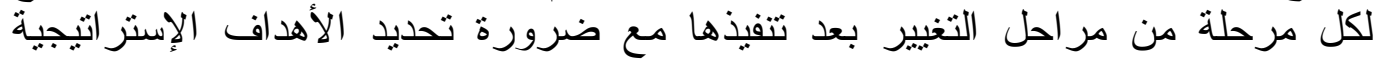

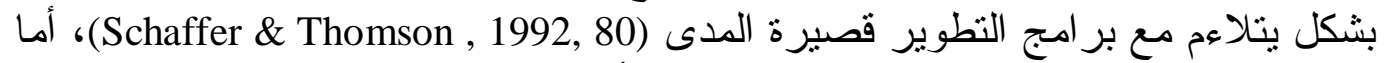
فقد تتاول هذه الظاهرة من خلال الأبعاد التي يمكن التعامل معها للسيطرة

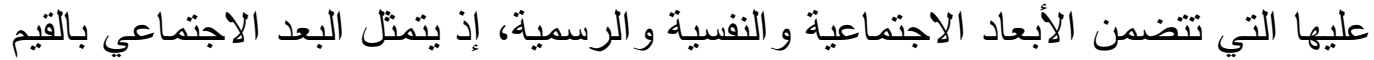

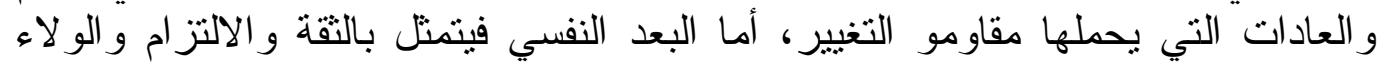

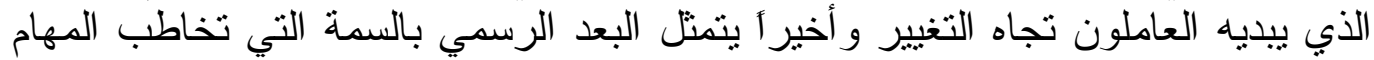

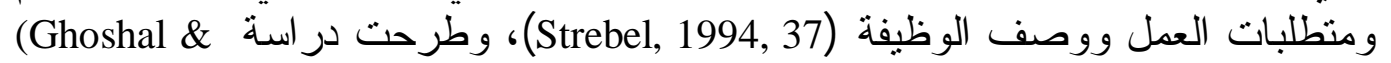

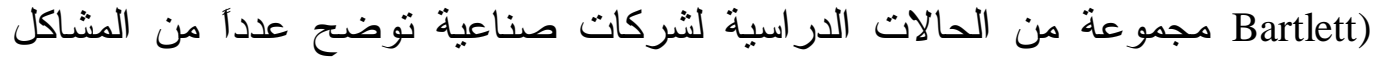
التي تواجه عملية التغيير في هذه الثركات، وتوصلت الدراسة إلى أنى أن تو افر أنظمة

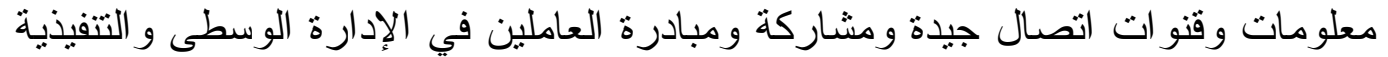

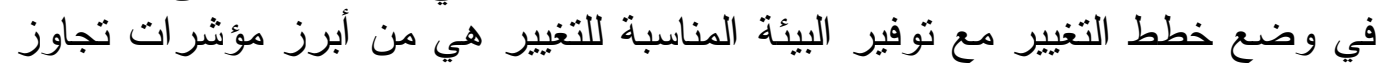

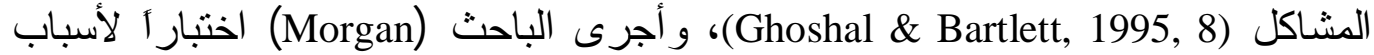

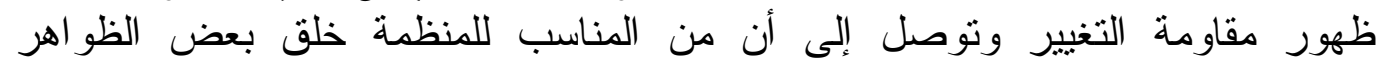

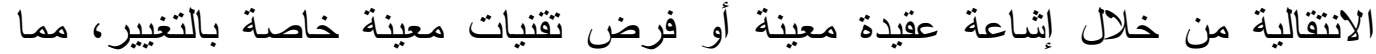

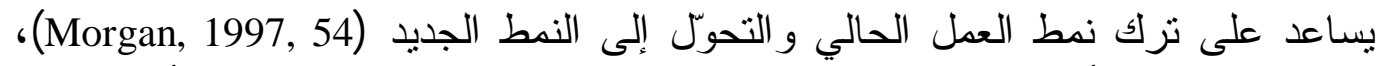
وتوصلت در اسة أجر اها الباحث (Coetsee) حول طبيعة ظاهرة المقاومة و أسبابها في

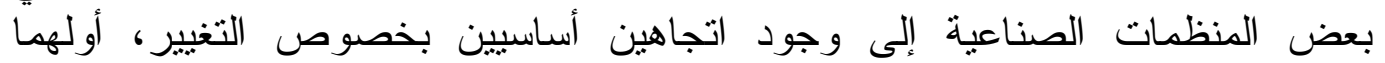
الالتز ام بالتغيير، وثانيهما مقاومة التغيير، وهذان الاتجاهان غير مرتبطين أنموذجياً،

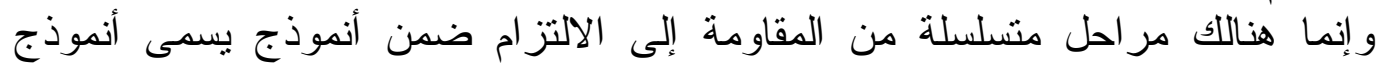


الاستمر ارية (Coetsee, 1999, 204)، و أخير أ قدم الباحث (Piderit) دراسة حول جذأدور

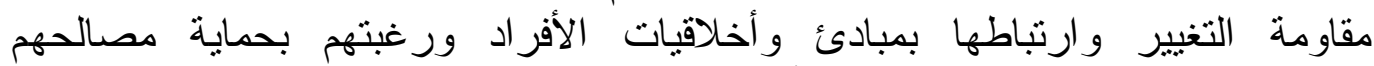

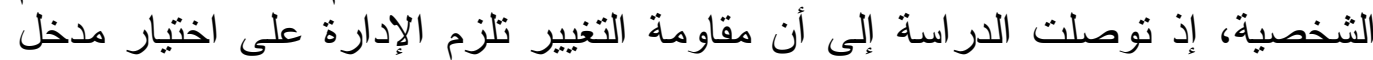

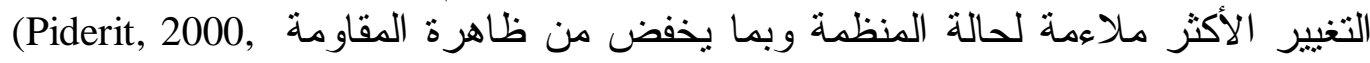

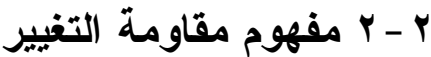

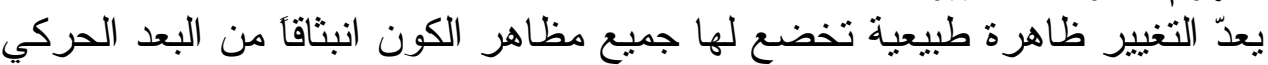

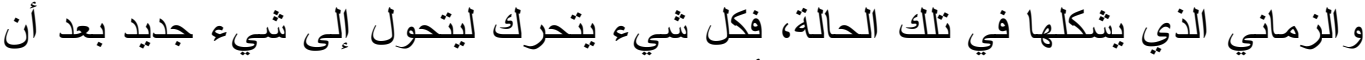

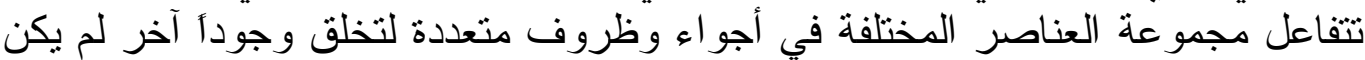

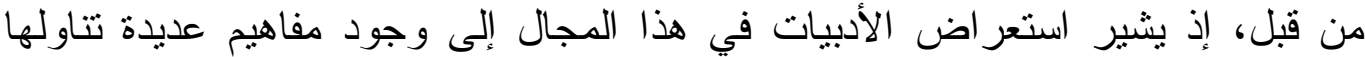
الباحثون كل حسب اتجاهه، إذ تتفق غالبيتها على عدّ التغيير تعديلا في الكيان التنظيمي

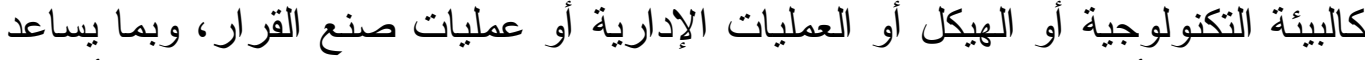

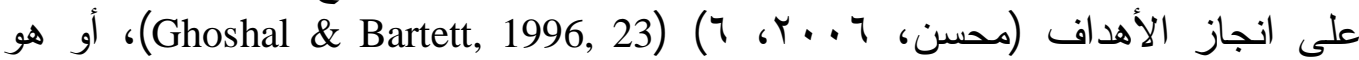
إيجاد طر ائق و أساليب جديدة في التفكير و التمثيل و التشغيل لإنجاز الأهداف المخططة

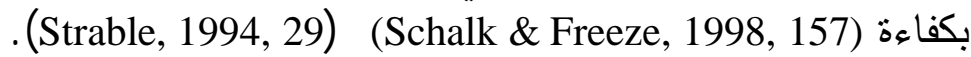

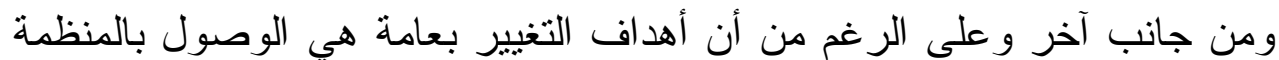

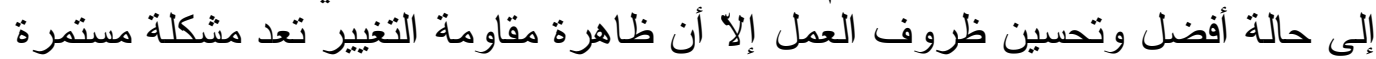

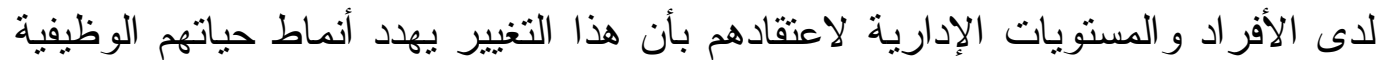

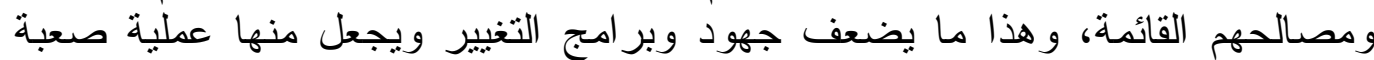
تؤدي إلى حدوث مشاكل داخل الوحدات التتظيمية التي ترغب بالتغيير التي تقود إلى التى

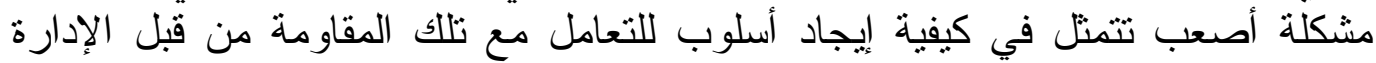
وخلق المناخ التنظيمي الذي يخفض من هذه المقاومة وبشكل ايجابي، يلاقي دعماً وقبو لا

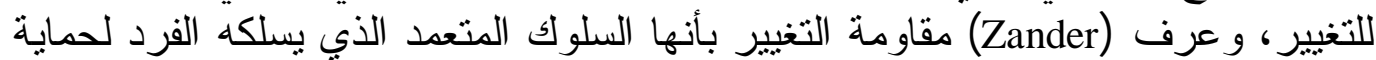
نفسه من أثنار التغيير الحقيقية أو الوهية (Zander, 1972, 669)، في حين أكداو (Ansoff)

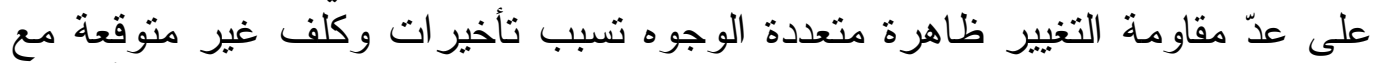

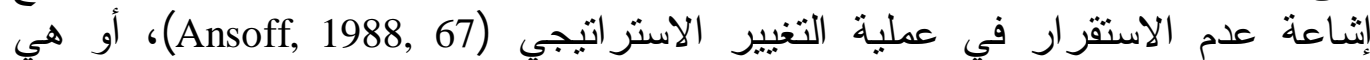

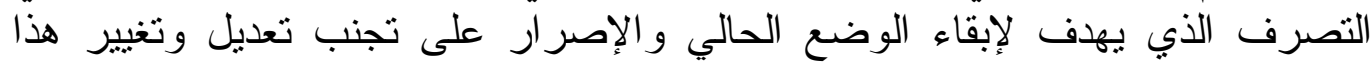
الوضع (Folger \& Sharilick, 1999, 35)، و انسجامأ مع ما تقدم يرى الإنى الباحث بأن ظاهرة

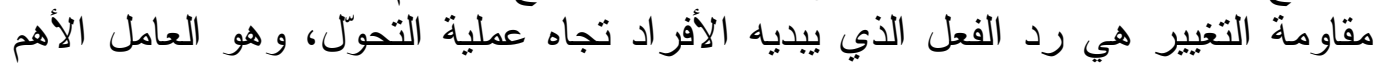
في تحقيق التوازن بين حالتي الاستقر ار و التغيير وغالباً ما تظهر لتفرئ لتفادي حالتي الركود

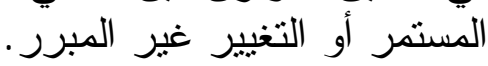


r r r أشكال مقاومة التغييز

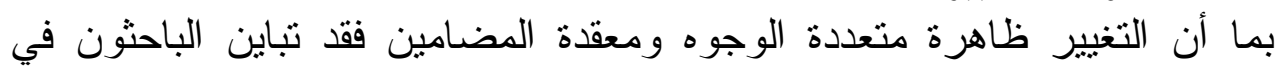

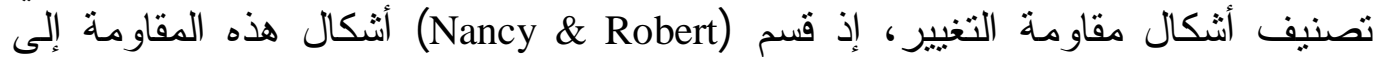

أربعة أنو اع أساسية وهي: (Nancy \& Robert, 2000, 42) أ. مقاومة التغيير العملياتي: و المرتبط بأسلوب وكيفية أداء العباء العمل و إجر اءاته التقصيلية المتلاحقة و المتر ابطة.

ب. مقاومة التغيير الثقافي: ويتمنل هذا الثكل من المقاومة بالسعي ضد الفلسفة التظظيمية التي تتبناها الإدارة في العمل.

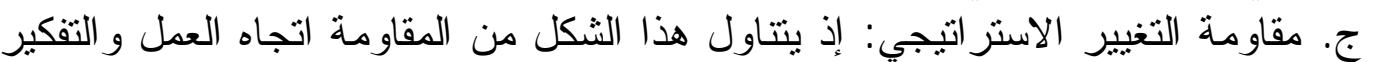
الاستر اتيجي الذي تسعى المنظمة لاعتماده.

د. دقاومة التغيير السياسي: وهذا ما يتعلق بالتغييرات الحاصلة في المنادهي لأك الوظيفي للمنظمة و اتجاهاتها.

أما (Kirkman) فيصنف أشكال مقاومة التغيير إلى: (Kirkman, 2000, 75) أ. مقاومة التغيير التقاني: وتتضمن مقاومة الأفر اد للتقانات الداخلة إلى المنظمة حديثأ و العمليات التابعة أو المرتبطة وتئة بها. ب. مقاومة التغيير في الأفر اد: وتشتمل على مقاومة نقل وتغيير العاملين من قسم إلى الى الى آخر أو من منظمة إلى أخرى ج. مقاومة تغيير المسؤوليات و الصلاحيات: ويعد هذا التغيير من أسهل الأشكال مما قد

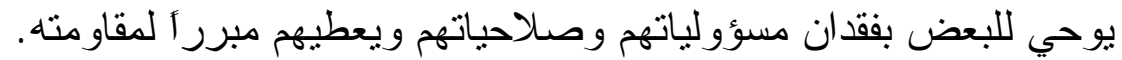

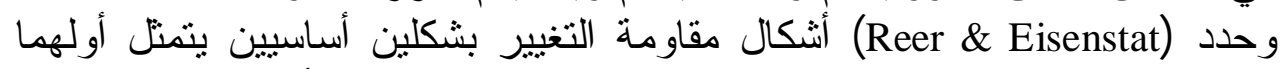

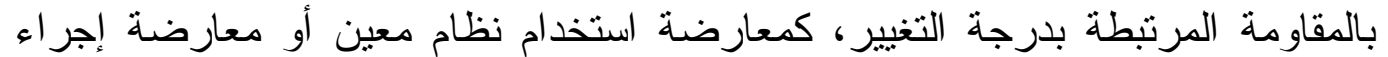

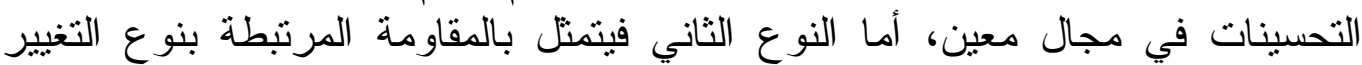

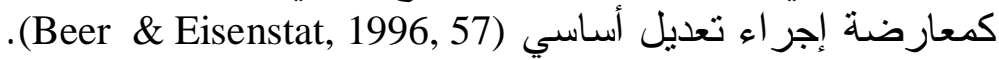
أما (Maurer, 1996, 60) فقد نتاول أتنكال مقاومة التغيير من خلأل الجوانب الآتية: - ماتية أ. مقاومة تغيير الأفر اد: وتتمنل بمناهضة سياسات النقل و إحلال العاملين. ب. مقاومة تغيير الجماعات: ونتشمل مقاومة نتكيل اللجان الوظيفية ومقاومة الوفيل تشكيل

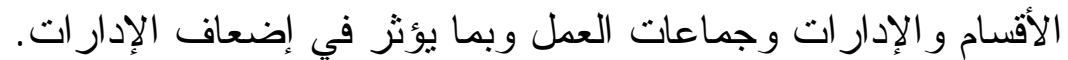

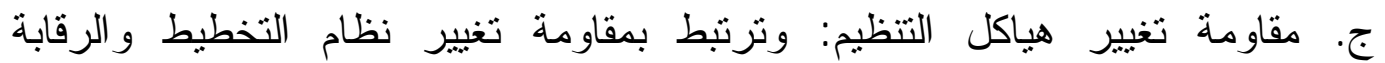

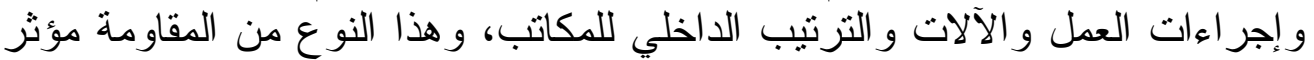
جدأ في حياة المنظمة.

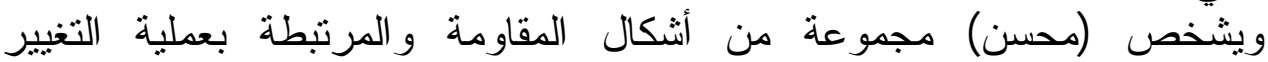

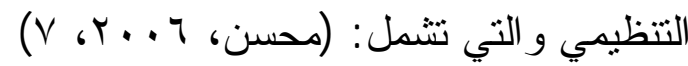
أ. مقاومة تغيير هدف المنظمة: وتتعلق بمقاومة خلق رسالة المنظمة و أهدافها. 
ب. مقاومة تغيير التكنولوجيا: وتتضمن مقاومة تغيير المعدات و التسهيلات وتحسين

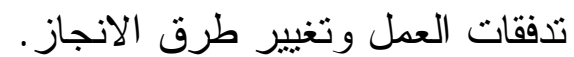

ج. مقاومة تغيير الإستر اتيجية: وتتضمن مقاومة العاملين لتغيير الخطط الإستر اتيجية

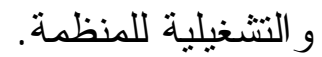

د. مقاومة تغيير الهيكل: ويشتمل على مقاومة تغبير علاقات السلطة ودرجة المركزية

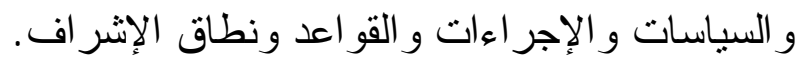

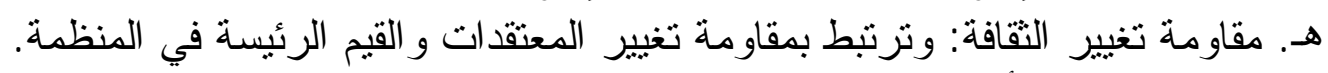

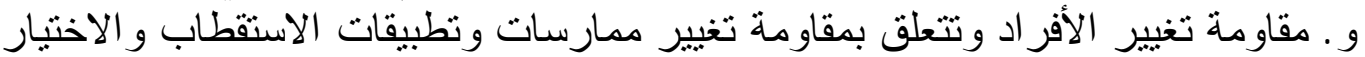

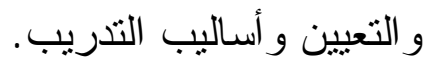

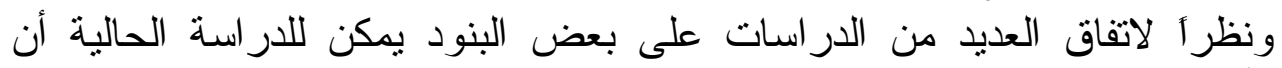
تصنف أثنكال مقاومة التغيير إلى التى الآتي: أ. مقاومة تغيير الهيكل التتظيمي وتتضمن المقاومة التي يبديها العاملون تجاه تغيير

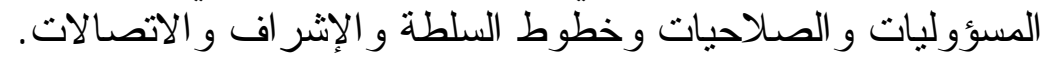

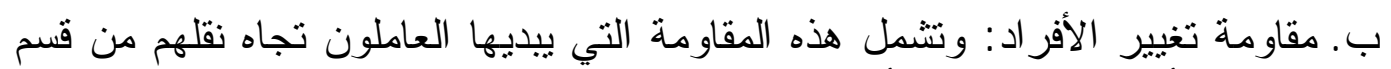

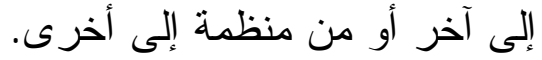
ج. مقاومة التغيير التقاني: ويرتبط هذا النوع بمقاومة العاملين لإدخال معدات و أساليب

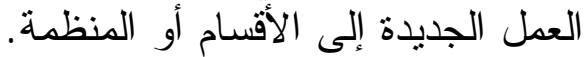

Y - ـ مصادر مقاومة التغييز

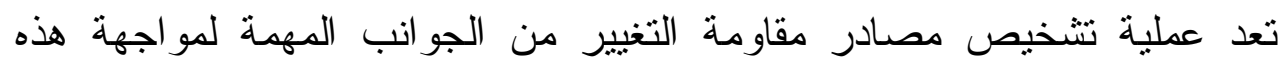

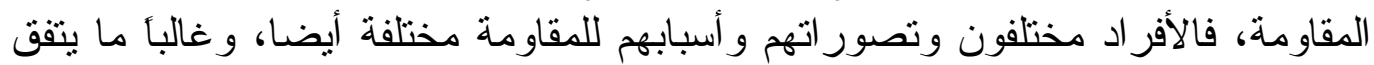

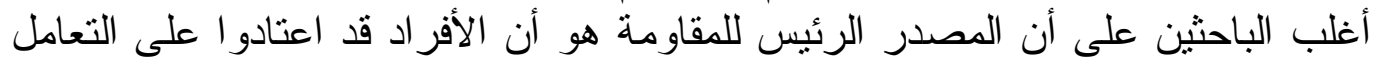

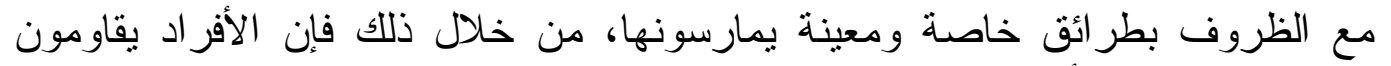

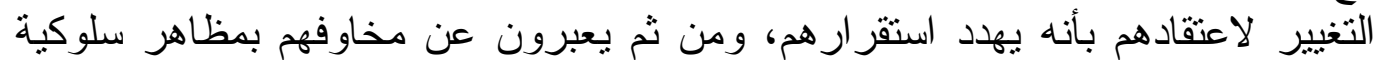

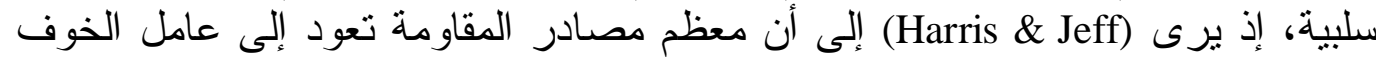
من أن يسبب التغيير نقصاً في أحد أو أكثر المجالات الآتية: , Harris \& Jeff, 1976)

أ. فقدان الحب و الاحتر ام و:يظهر من خلال فقدان حـ ب الآخرين واحتر امهم إياه ونقص

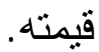

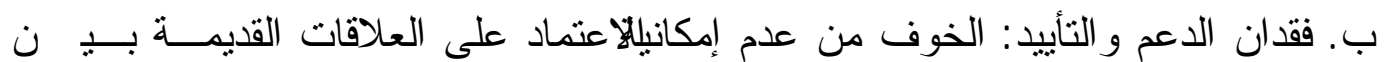
الجماعات.

ج. فقدان الإحساس بمعرفة المتغير ات: عدم حصول الفرد على المعلومات المطلوبة مما

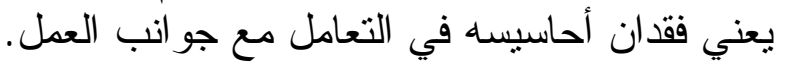
د. فقدان القدرة على العمل : عدم قدرة الفرد على القيام بعمله أو التأثير فـــي الآخــرين بحيث يصبح الفرد أكثر تضحية و أقل تحكماً في مصنيره. 
أما الباحثان (Werther \& Keith) فيتتاو لا المصادر من خلال ثناثة محاور أساسية،

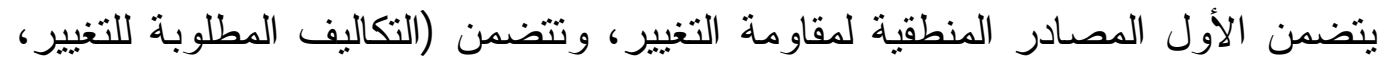

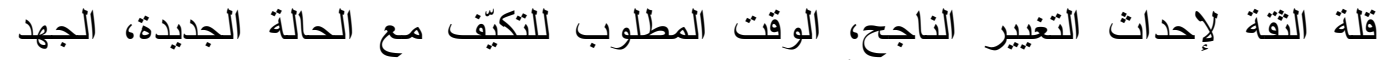

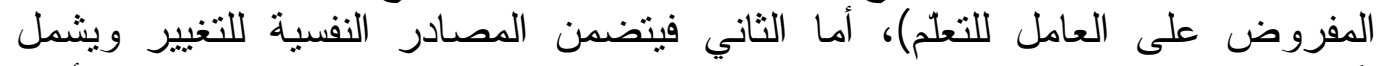

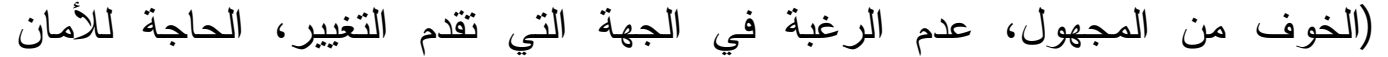
و المحافظة على الوضع الر اهن، قلة الثقة بالآخرين)، أماً الثالث فهو الثمانة المصادر الاجتماعية

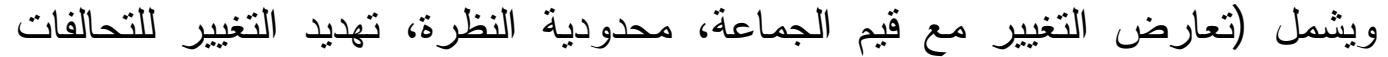

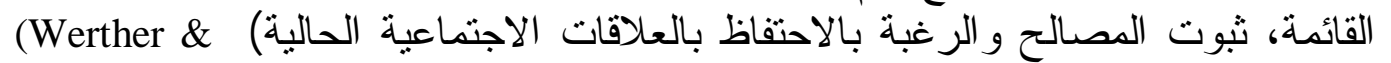
(Milton \& Entrekin) مصادر مقاومة التغيير من وتناول

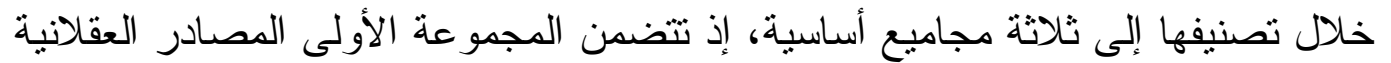

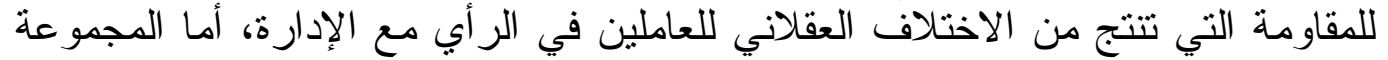

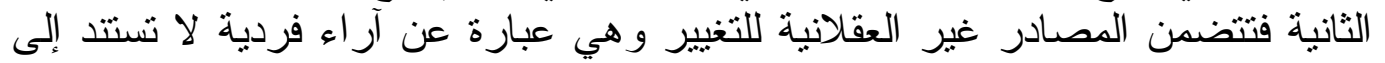
تقييم عقلاني للتغيير مع عدم الرغبة و القلق من تطبيق التغيير الجديد ونتائجه، في حين الأني

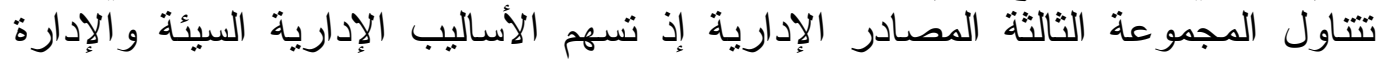

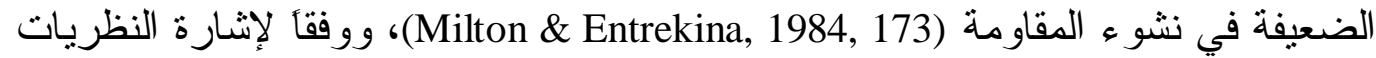
التضمينية يرى الباحثان (White \& Bednar) أن مصادر مقاومة التغيير ربما تتعكس من

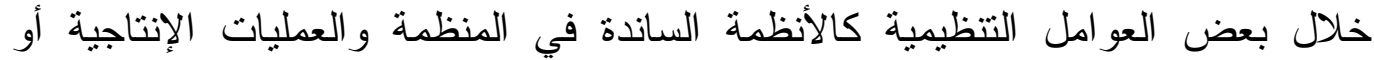

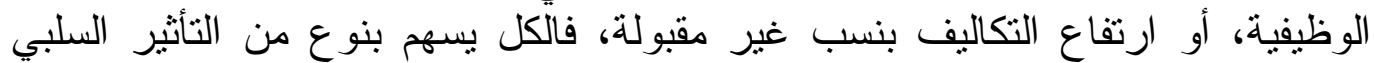
باتجاه إضعاف المنظمة لإحداث التغيير المطلوب (White \& Bednar, 1991, 154).

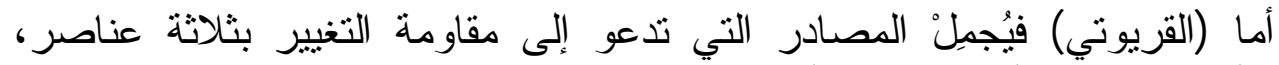
يتمثل الأول بانعدام الأمان وذلك لأن التغيير معناه ظروف غير معروفة النتائج تهدد

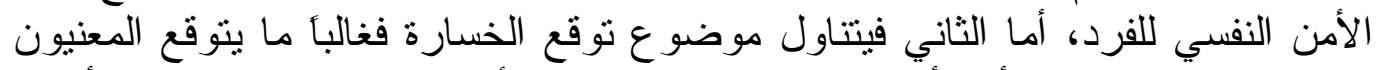

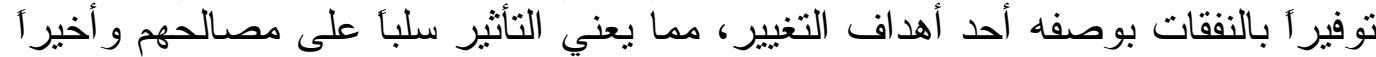

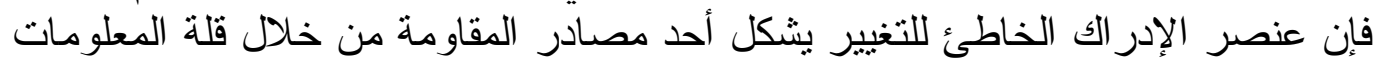

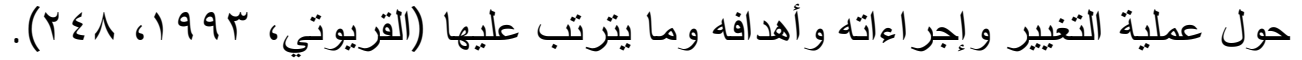

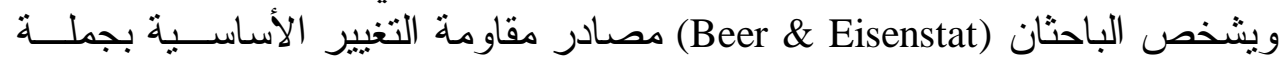

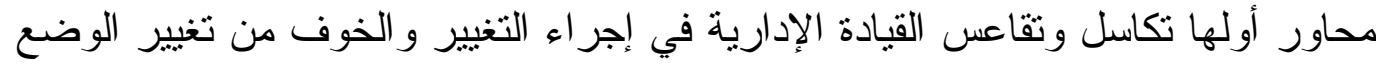

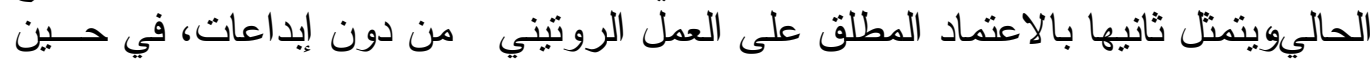

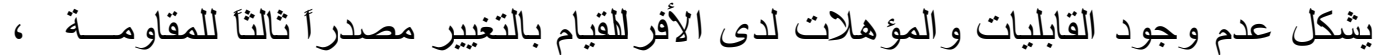

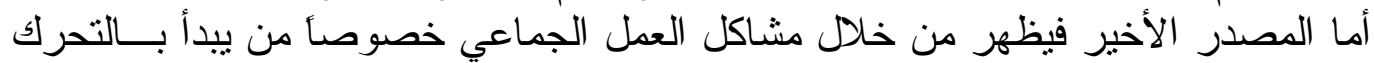

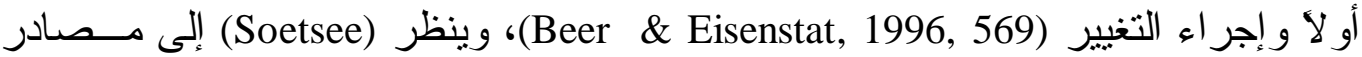

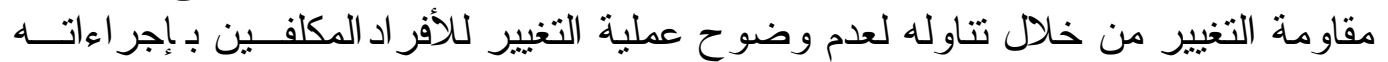

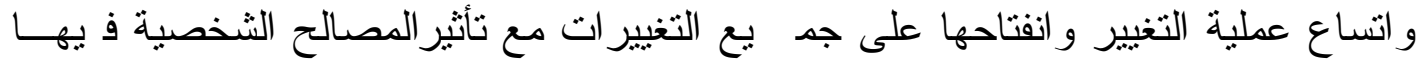

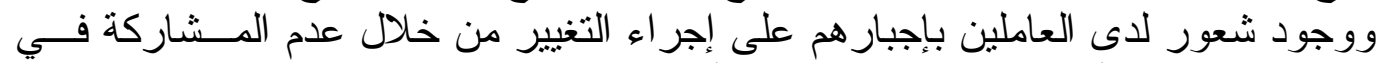
صناعة قر ار اته و أخير آ إهمال المتطلبات الأساسية لعملية التغيير (Coetsee, 1999, 205). 


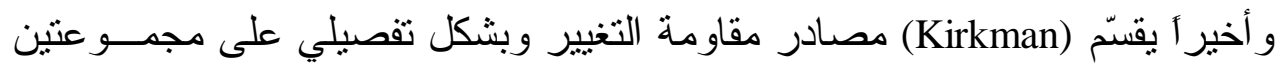

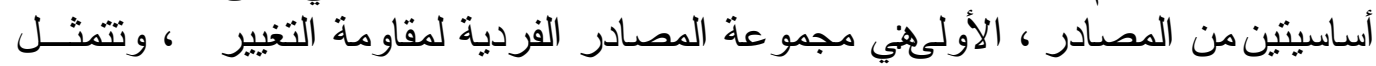

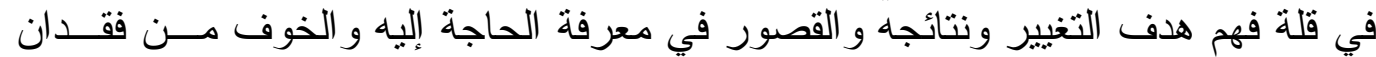

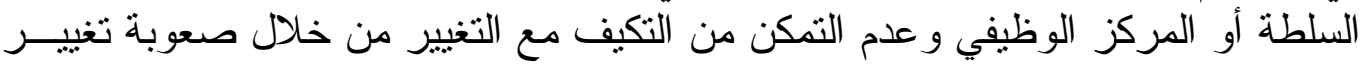

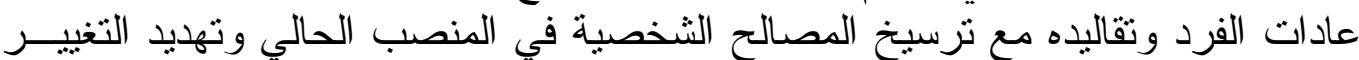

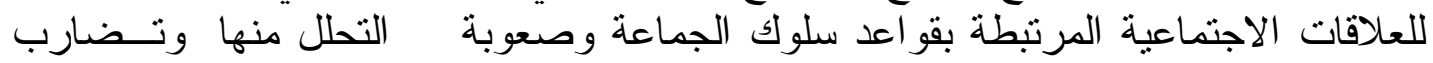

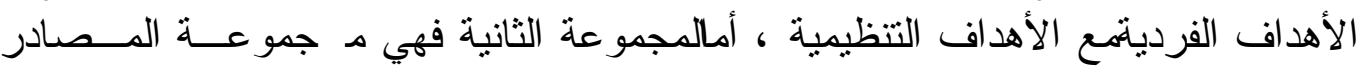

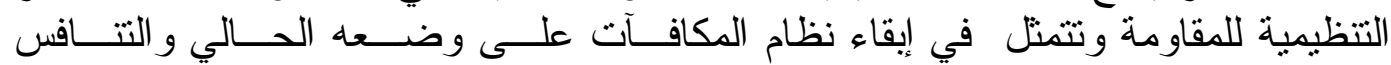

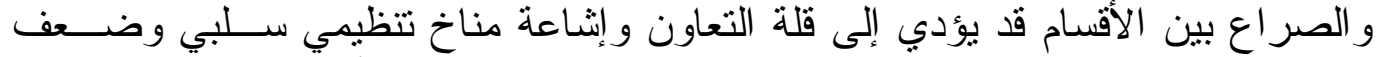

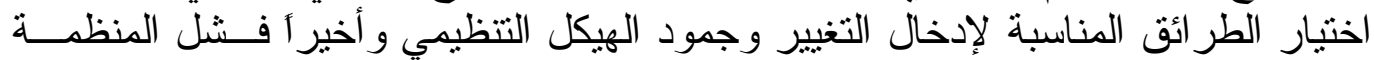
في محاو لات التغيير السابقة (Kirkman, 2000, 83).

\section{r -ه مداخل إدارة مقاومة التغيير}

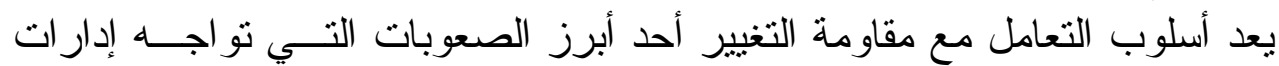

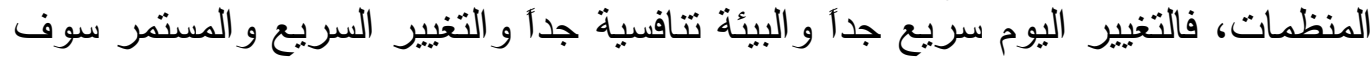

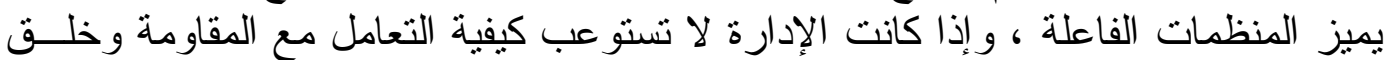

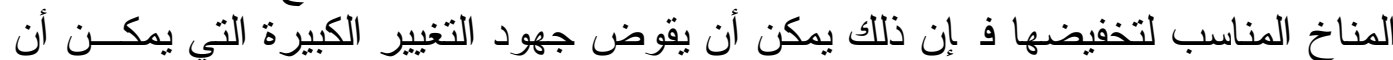

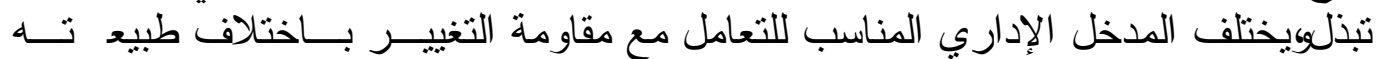

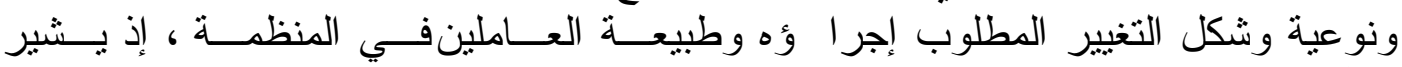

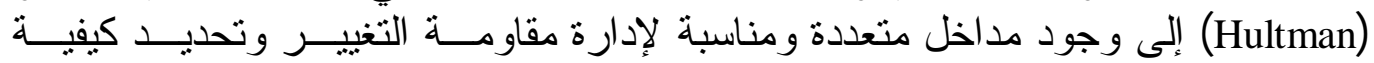
التعامل معه تتمثل بالآتي: (Hultman, 1995, 17) أ. مدخل بناء فريق التغيير: ويعتمد هذا المدخل على بلى اختيار الأفراد الكفوئين الذين

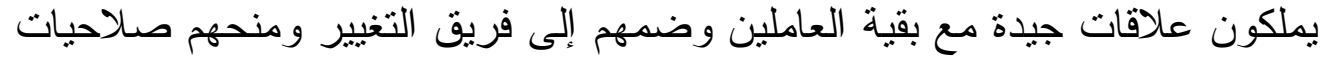

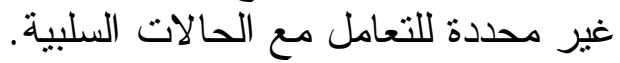

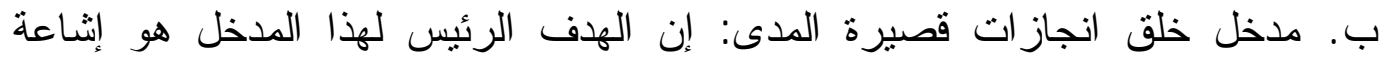

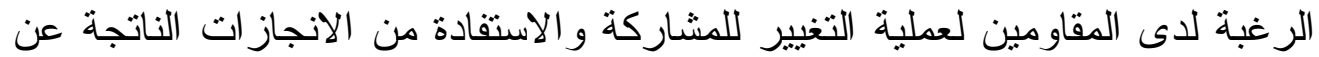

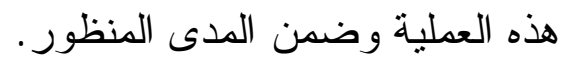
ج. مدخل بناء ثقافة التغيير: ويقوم هذا المدخل على إرساء إلى مبادئ التغيير و أهميته

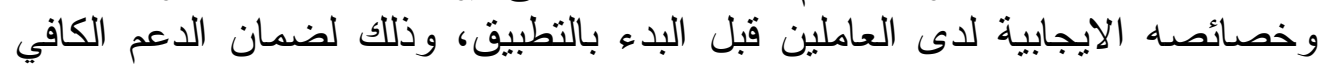

و المناسب لعملية التغبير و الالتز ام بها.

د. مدخل تعاقب إجر اءات التغيير : يتضمن هذا المدخل إجر اء عمليات التغيير بشكل متعاقب وبما يظهر للمقاومين جدية العملية وخلق نجاحات متلاحقة لإقناعهم بضرورة إجر اء التغيير .

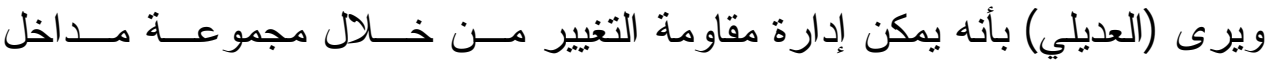


أ. مدخل النزكيز على التغيير المنطقي: إذ من المناسب جداً أن تقوم الإدارات باعتماد

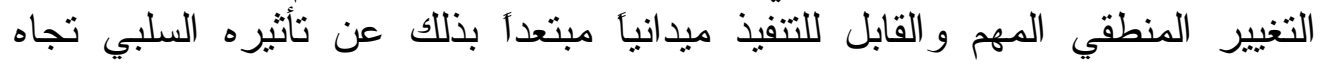
العاملين مما يخفض من مقاو متهـ.

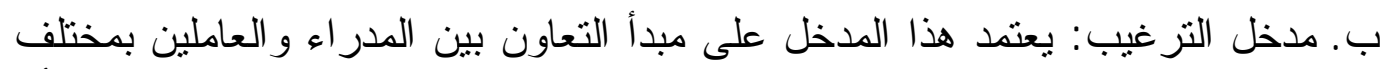

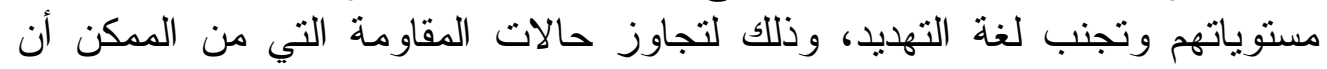
تظهر خلال إجر اءات التغيير.

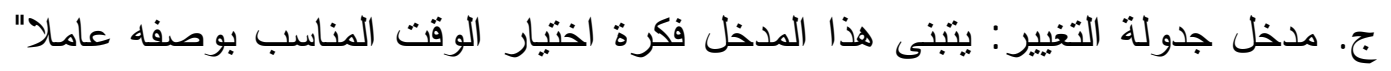

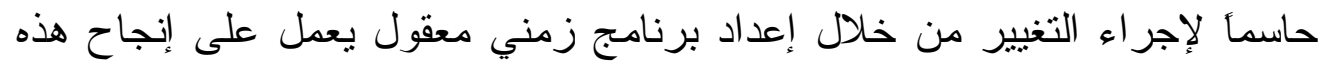

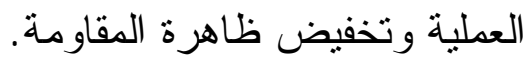

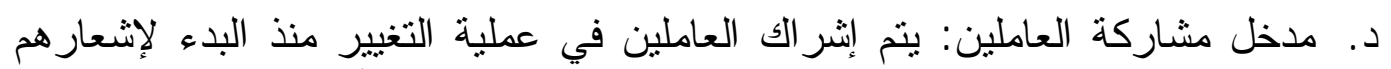

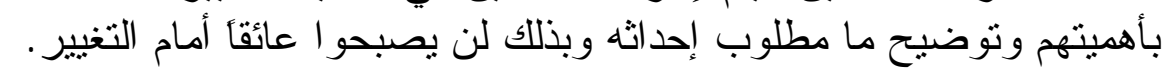

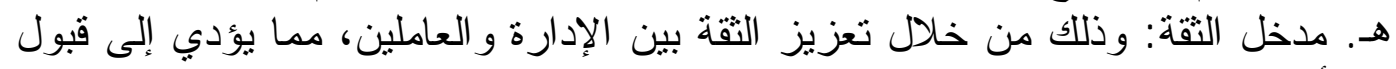

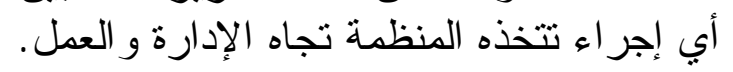

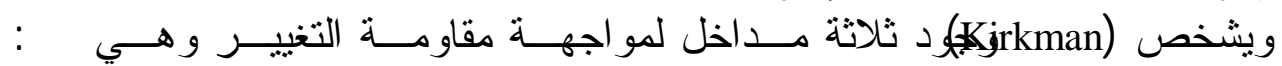

(Kirkman, 2000, 79)

أ. مدخل بناء نظام خاص للتحفيز : ويعتمد هذا المدخل على التعامل مع مقاومة التغيير

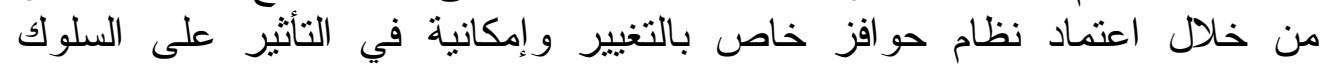
وتغييره نحو الاتجاه المطلوب.

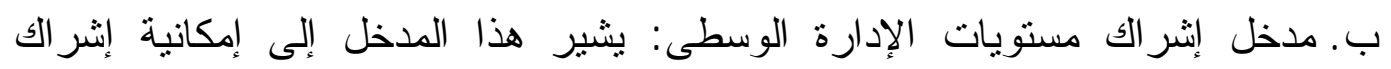

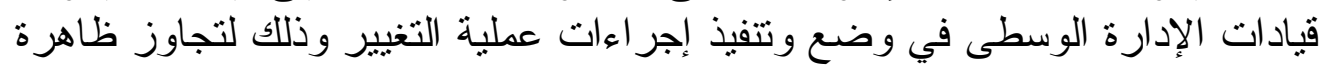

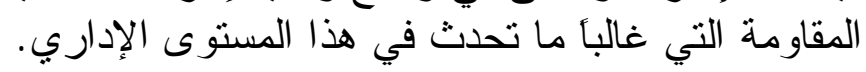

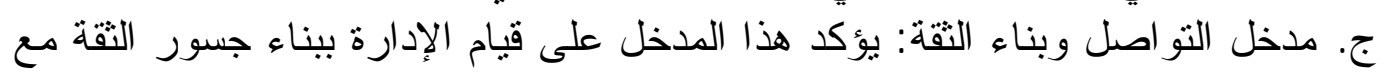

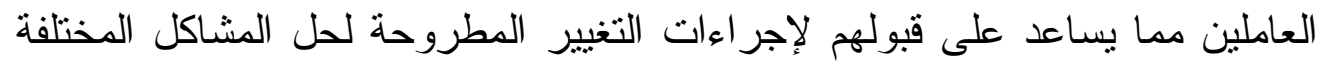

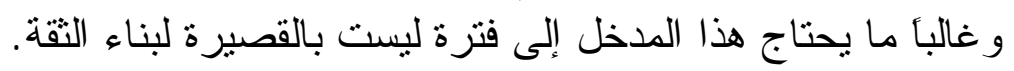

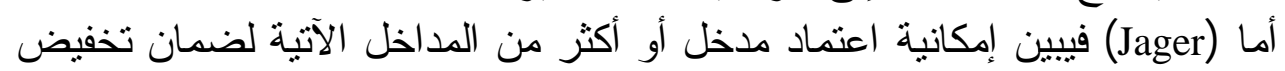

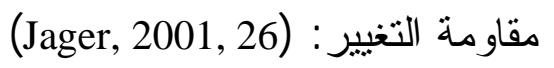

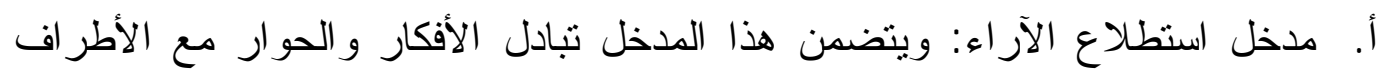

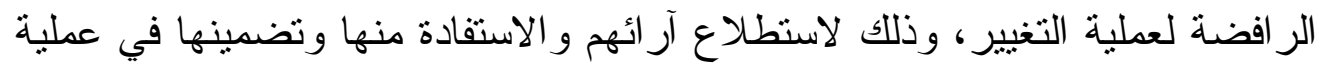
التغيير . التخان.

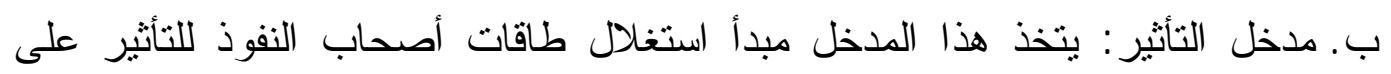

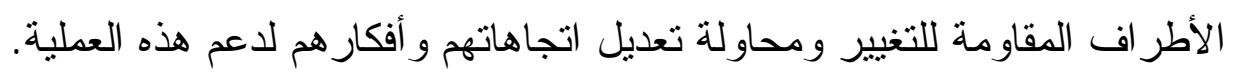

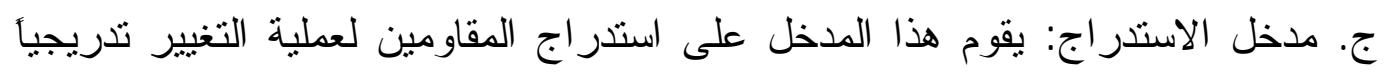
لتكليفهم بتتفيذ بعض جو الانب وتو و إجر اءات عملية التغيير ودمجهم بهذه العملية. 
د. مدخل إظهار الأخطاء: يعتمد هذا المدخل على مبدأ الاستمرار بطرح مشاكل

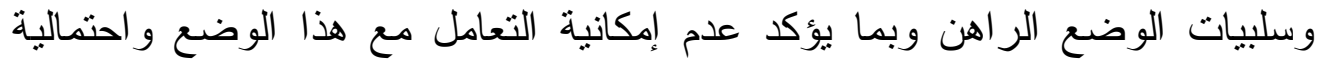

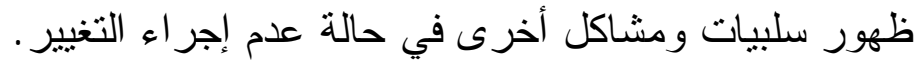

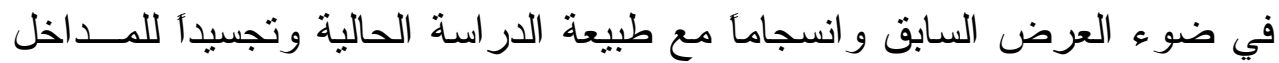

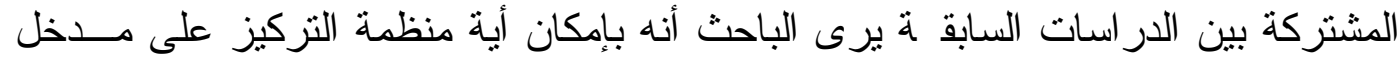
أو أكثر من المداخل الآتية وتبعأ للظروف لإليف البيئية السائدة:

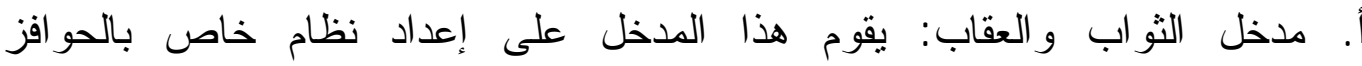
(بأشكالها كافة) يرتبط بإجر اءات عملية التغيير .

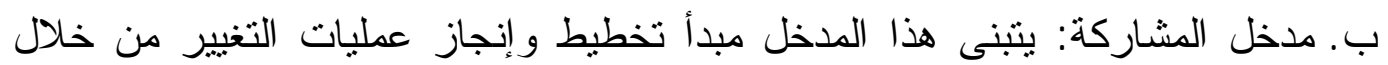
مشاركة العاملين ومسؤولي الوحدات الإدارية كافة في المنظمة ودر اسة مشاكلهم بخصوص هذه العملية. ج. مدخل جدولة التغيير : يعتمد هذا المدخل على وضع جداول محددة بتوقيتات زمنية

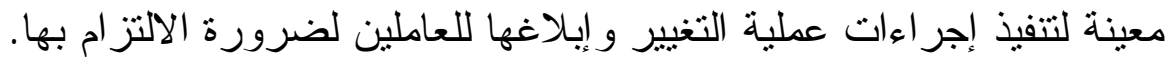
د. مدخل نشر ثقافة التغيير : يتضمن هذا المدخل تزويد العاملين بالمعارف عن عملية التغيير و مبادئها و أهدافها و أدو ار هم المكلفين بها. هـ. مدخل بناء التقة: يقوم هذا المدخل على الإيمان الكامل بقدرة العاملين لانجاز التغيير و إمكانيتهم على تتفيذ المهام الجديدة بعد التغيير .

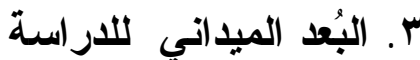

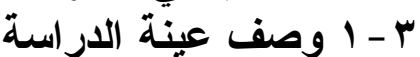

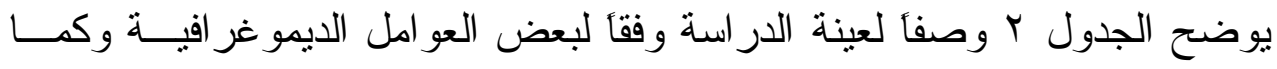
:بأنَي:

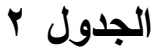

وصف عينة الاراسة وفقاً للعو امل الايموغر افية

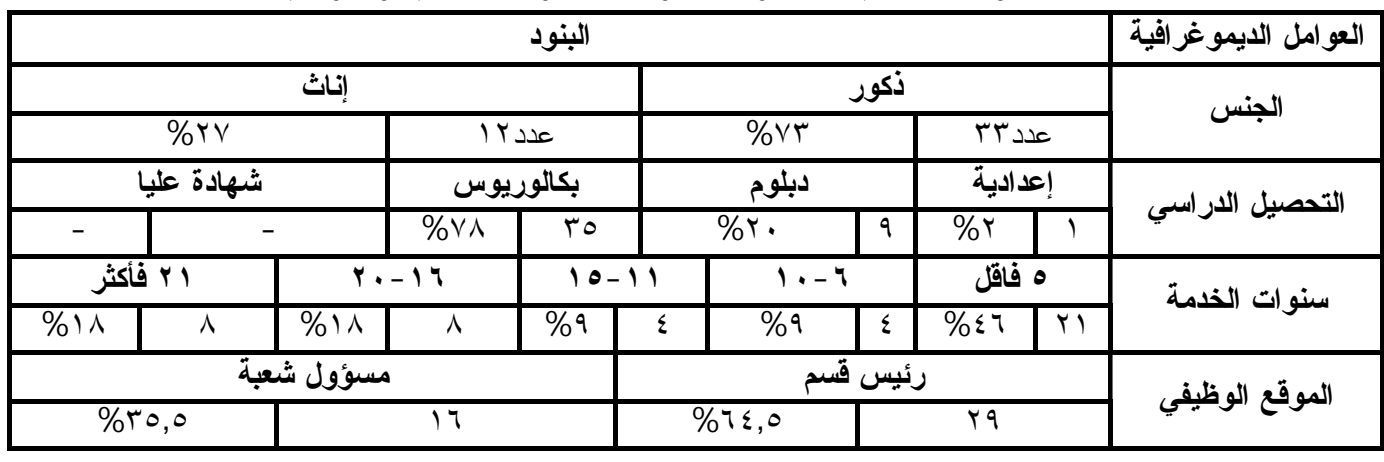




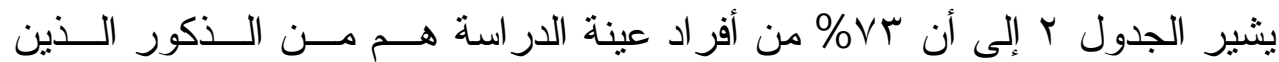

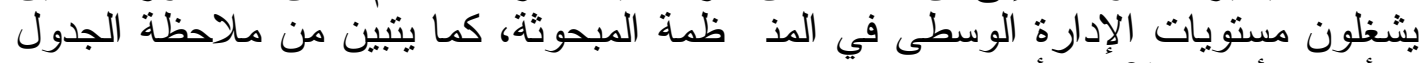

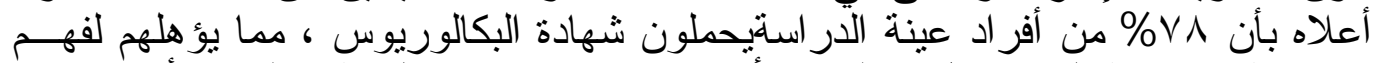

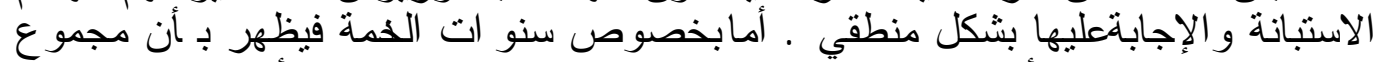

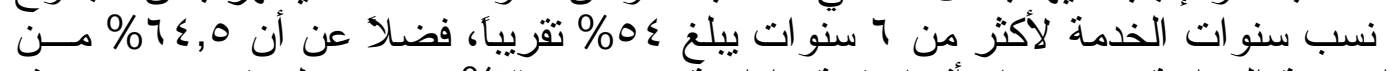

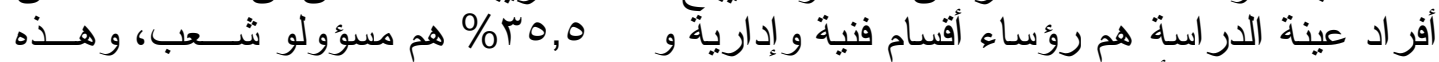

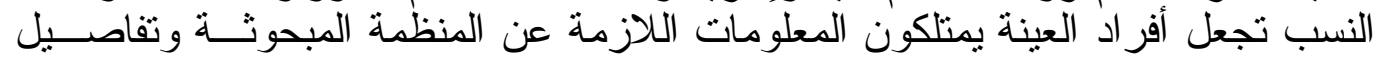

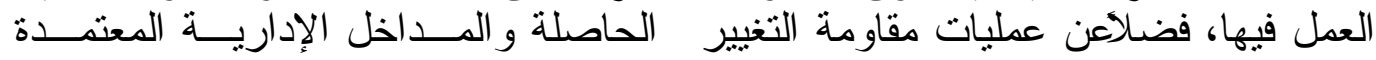
لمو اجنها.

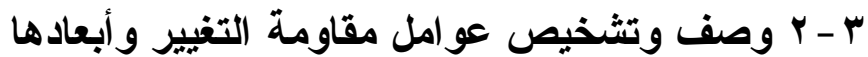

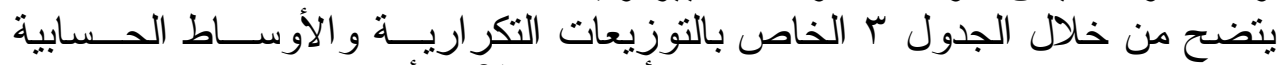

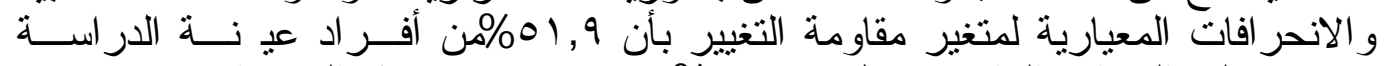

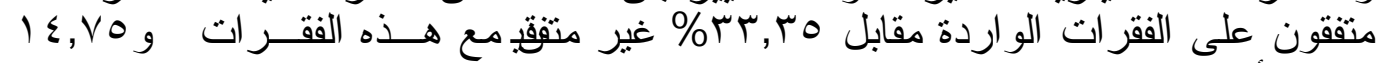

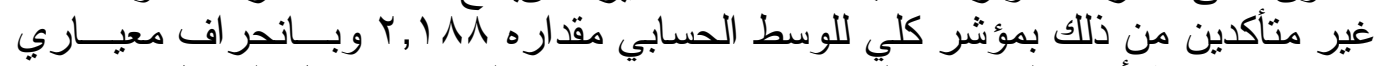

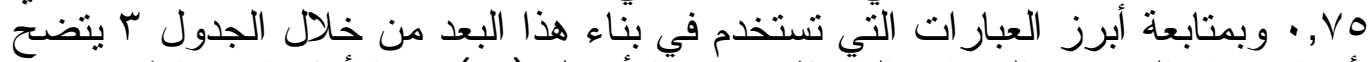

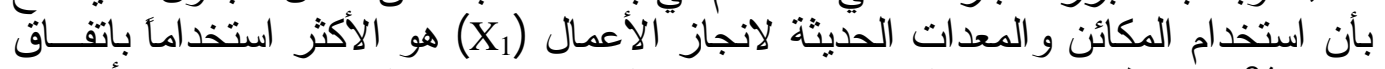

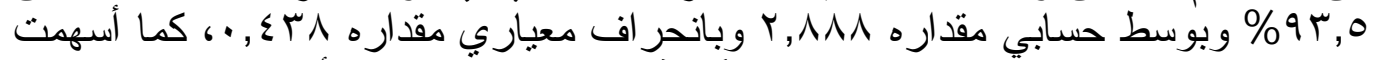

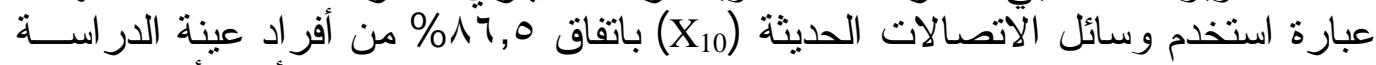

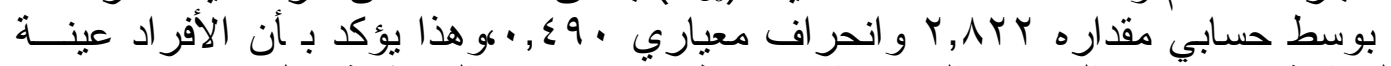

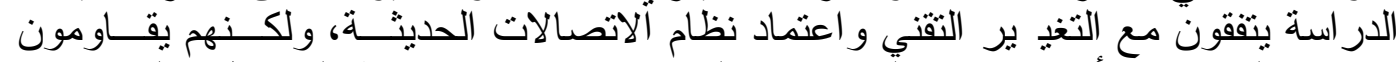

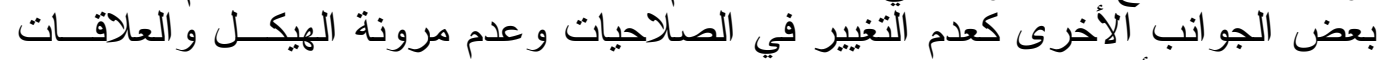

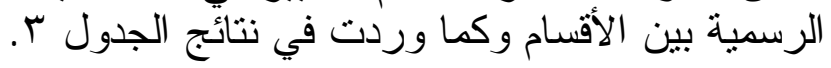

r - r وصف وتثخيص عوامل متغير المداخل الإدارية المواجهة لمقاومة التغيير

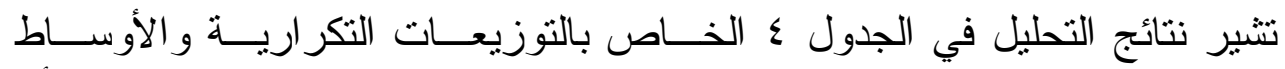

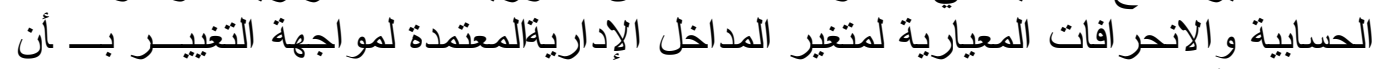

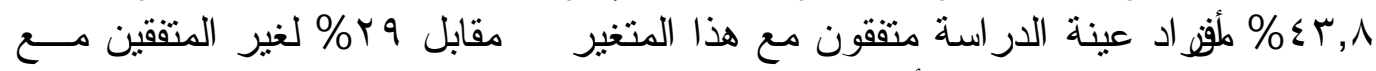

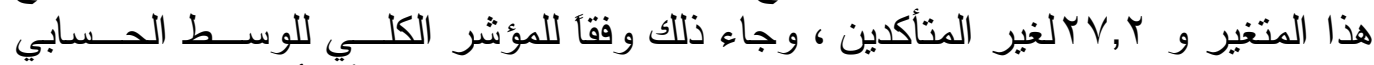

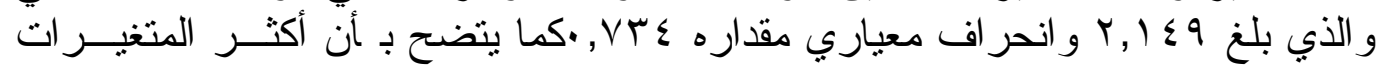

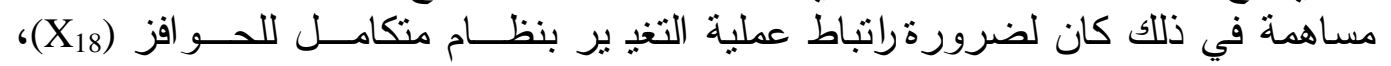

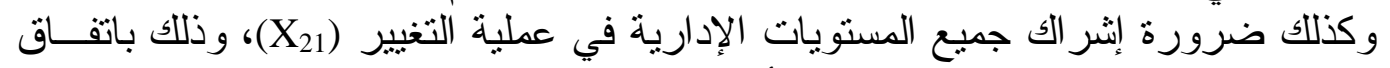

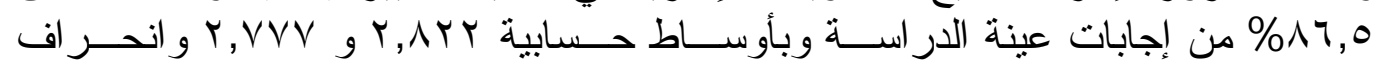

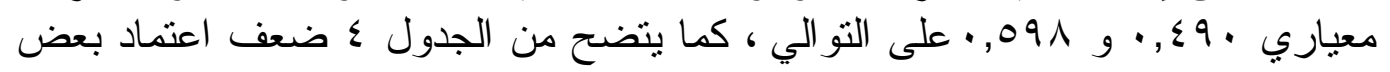

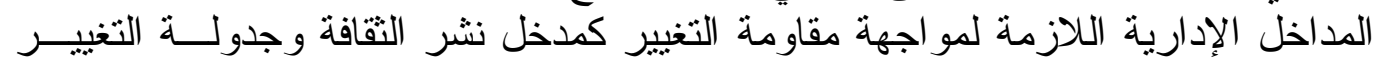

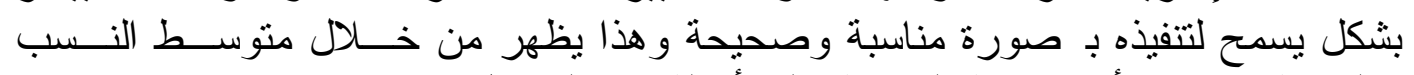

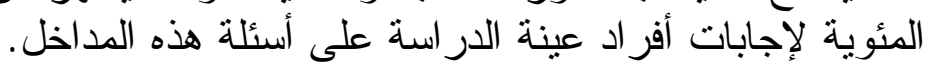




\section{الجدول rابلة}

التوزيعات التكرارية و الأوساط الحسابية و الاتحر افات المعيارية لعوامل مقاومة التغيير

\begin{tabular}{|c|c|c|c|c|c|c|c|c|c|}
\hline \multirow{2}{*}{ الالمعر اف المعياري } & \multirow{2}{*}{ الحسط } & \multicolumn{2}{|c|}{ لا اتفق } & \multicolumn{2}{|c|}{ غير متأكد } & \multicolumn{2}{|c|}{ اتقق } & \multirow{2}{*}{ المتغير ات الفرعية } & \multirow{2}{*}{ أشكال } \\
\hline & & $\%$ & العدد & $\%$ & العدد & $\%$ & العدد & & \\
\hline$\cdot, \varepsilon \Gamma \wedge$ & $\uparrow, \wedge \wedge \wedge$ & $\varepsilon, 0$ & $r$ & $r$ & 1 & 94,0 & $\varepsilon r$ & $\mathrm{X} 1$ & \multirow{4}{*}{ التقانة } \\
\hline$\cdot, \Lambda \backslash \Gamma$ & $T, \varepsilon \leqslant \varepsilon$ & $r$. & $\overline{9}$ & 17 & $\bar{V}$ & $7 \varepsilon$ & rq & $\mathrm{X} 2$ & \\
\hline$\cdot, 91 \mathrm{~V}$ & $1,9 \vee \wedge$ & $\sum T$ & 19 & 11 & $\bar{\Lambda}$ & $\varepsilon$. & 11 & X3 & \\
\hline$\cdot, \leqslant 0 \mathrm{~V}$ & $1,1 \Gamma T$ & 91 & $\sum 1$ & $\varepsilon, 0$ & $T$ & $\varepsilon, 0$ & $r$ & $\overline{\mathrm{X} 4}$ & \\
\hline$\cdot$, VOr & $r, O V \wedge$ & 17 & $\bar{V}$ & 11 & 0 & $\overline{V T}$ & $r r$ & $\mathrm{X} 5$ & \multirow{8}{*}{ التظظيكي } \\
\hline$\cdot, 9 \cdot 1$ & $r, Y \leq \leq$ & TI & $1 \varepsilon$ & $1 \Gamma, 0$ & 7 & 00,0 & Yo & $\mathrm{X} 6$ & \\
\hline$\cdot, 70 \mathrm{~T}$ & $1, \varepsilon$ & 79 & 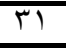 & Tr & 1. & 9 & $\varepsilon$ & $\mathrm{X} 7$ & \\
\hline$\cdot, V Y T$ & T,OMT & $T \pi, 0$ & 7 & $r$. & 9 & 77,0 & $r$. & $\mathrm{X} 8$ & \\
\hline$\cdot, 909$ & $r, \| 11$ & $\varepsilon$. & 11 & 9 & $\varepsilon$ & 01 & $T r$ & $\mathrm{X9}$ & \\
\hline$\cdot, \leqslant 9$. & T,AYY & $\varepsilon, 0$ & T & 9 & $\varepsilon$ & 17,0 & rq & $\mathrm{X} 10$ & \\
\hline$\cdot, 7 \vee \leqslant$ & T,T7V & 11 & 0 & 11 & 0 & $\nabla \wedge$ & ro & $\mathrm{X} 11$ & \\
\hline$\cdot, V Y O$ & 1,007 & 7. & TV & rq & $\pi$ & 11 & 0 & $\mathrm{X} 12$ & \\
\hline$\cdot, \wedge 9 \uparrow$ & $r, \cdot Y r$ & rA & IV & YY & 1. & $\varepsilon$ & 11 & $\mathrm{X} 13$ & \multirow{4}{*}{ الأفر اد } \\
\hline$\cdot$, AOr & $r, \cdot \varepsilon \leqslant$ & Tr & 10 & rq & $1 \pi$ & $r \wedge$ & IV & $\mathrm{X} 14$ & \\
\hline$\cdot, \wedge \xi 1$ & $r, 007$ & Tr & 1. & - & - & $\nabla \wedge$ & ro & $\mathrm{X} 15$ & \\
\hline$\cdot, 9 \cdot r$ & $r, \cdot \leq \varepsilon$ & $r \Lambda$ & IV & $r$. & 9 & $\sum T$ & 19 & $\mathrm{X} 16$ & \\
\hline$\cdot, \vee \vee 0$. & $r, 1 \wedge \wedge$ & rr, & 10 & $1 \varepsilon, 10$ & V & 01,9 & $r T$ & & المؤا' \\
\hline
\end{tabular}

\section{الجدول ؛}

التوزيعات التكر ارية و الأوساط الحسابية والانحر افات المعيارية لعوامل المداخل الإدارية

\begin{tabular}{|c|c|c|c|c|c|c|c|c|c|}
\hline \multirow{2}{*}{ الالمعراف } & \multirow{2}{*}{ الحسابي } & \multicolumn{2}{|c|}{ لا اتفق } & \multicolumn{2}{|c|}{ غير متأكد } & \multicolumn{2}{|c|}{ اتفق } & \multirow{2}{*}{ المتغير ات الفرعية } & \multirow[t]{2}{*}{ المداخل الإدارية } \\
\hline & & $\%$ & العدد & $\%$ & العدد & $\%$ & العدد & & \\
\hline$\cdot, 101$ & $1, \varepsilon$ & Vo & T\& & 9 & $\varepsilon$ & 17 & $\bar{V}$ & $\mathrm{X}_{17}$ & \multirow{4}{*}{ مدخل الثواب } \\
\hline$\cdot, \leqslant 9$. & T,AYY & $\varepsilon, 0$ & $T$ & 9 & $\varepsilon$ & 17,0 & rq & $\mathrm{X}_{18}$ & \\
\hline$\cdot, 1 \times 79$ & $T, \cdot$ & rq & $\pi$ & $\varepsilon r$ & 19 & 19 & $\pi$ & $\mathrm{X}_{19}$ & \\
\hline$\cdot, \Lambda T V$ & Y,YTV & $r \leqslant, 0$ & $\pi$ & $T \leqslant, 0$ & 11 & 01 & Tr & $\overline{X_{20}}$ & \\
\hline., 091 & Y,VVV & 9 & $\varepsilon$ & $\varepsilon, 0$ & T & 17,0 & $r q$ & $\overline{X_{21}}$ & \multirow{4}{*}{ مدخل المشاركة } \\
\hline$\cdot, \wedge \wedge \uparrow$ & T,AYY & ह9 & TY & TY & T. & rq & $\pi$ & $\mathrm{X}_{22}$ & \\
\hline$\cdot, V I T$ & $Y, Y \leqslant \varepsilon$ & 17 & $\bar{V}$ & $\varepsilon \varepsilon$ & $r \cdot$ & $\varepsilon$ & 11 & $\overline{X_{23}}$ & \\
\hline$\cdot, \times 17$ & T,TYY & $1 \Gamma, 0$ & 7 & $\pi$ & 0 & Vo & $r \varepsilon$ & $\mathrm{X}_{24}$ & \\
\hline$\cdot, \Lambda \cdot \varepsilon$ & $r, 111$ & $T \xi, 0$ & $\pi$ & $r 0,0$ & 17 & $\varepsilon$ & 11 & $\overline{X_{25}}$ & \multirow{4}{*}{ مدخل نشّر } \\
\hline$\cdot$, VरO & $T, \varepsilon \leqslant \varepsilon$ & $1 \Gamma, 0$ & 7 & rq & $\pi$ & $0 V, 0$ & T7 & $\mathrm{X}_{26}$ & \\
\hline$\cdot, 7 \leq 9$ & $1, T Y Y$ & $\varepsilon V$ & Tा & $\varepsilon \varepsilon$ & $r$. & 9 & $\varepsilon$ & $\mathrm{X}_{27}$ & \\
\hline$\cdot, \vee \vee \wedge \neg$ & 1, ATV & $\Gamma \wedge$ & TV & rर & TV & $T \leqslant, 0$ & $\pi$ & $\overline{X_{28}}$ & \\
\hline$\cdot, \Lambda \cdot Y$ & $1,7 \leq \varepsilon$ & 00,0 & To & $T \leqslant, 0$ & 11 & T. & 9 & $\mathrm{X}_{29}$ & \multirow{3}{*}{ مدخل بناء الثقة } \\
\hline$\cdot, V \leq T$ & Y,Y07 & 17 & $\bar{V}$ & TT & 10 & 01 & Tr & $\overline{X_{30}}$ & \\
\hline$\cdot, \mathrm{V01}$ & $T, \xi$ & 17 & $\bar{V}$ & rq & $T$ & 00 & To & $\mathrm{X}_{31}$ & \\
\hline$\cdot, V \vee T$ & $1,7 \leqslant \varepsilon$ & Or & $T \varepsilon$ & 19 & $1 T$ & 11 & $\lambda$ & $\mathrm{X}_{32}$ & \multirow{3}{*}{ مدخل جدولة } \\
\hline$\cdot, \Lambda T V$ & $T, \cdot T V$ & Tा & $1 \varepsilon$ & $\Gamma$ & $1 \varepsilon$ & Th & TV & $\mathrm{X}_{33}$ & \\
\hline$\cdot, 0 \wedge T$ & T,OVV & $\bar{V}$ & $\Gamma$ & TI & $1 \varepsilon$ & $T Y$ & TA & $\overline{X_{34}}$ & \\
\hline$\cdot, V Y \varepsilon$ & $r, 1 \leq q$ & rq & $\pi$ & $T V, Y$ & $T$ & $\varepsilon \Gamma, \Lambda$ & r. & & المؤشر \\
\hline
\end{tabular}




\section{r - ـ اختبار أنموذج الارسة وفرضياتها}

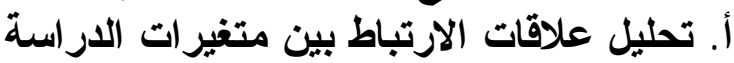

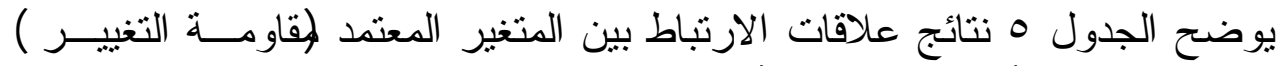

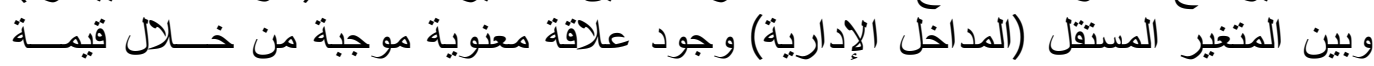

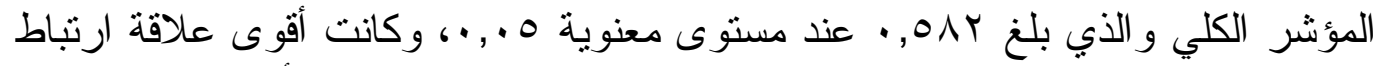

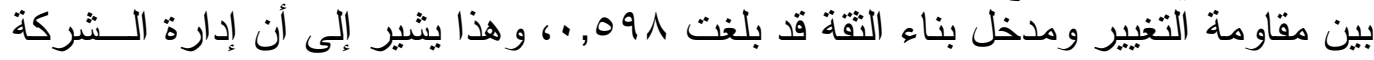

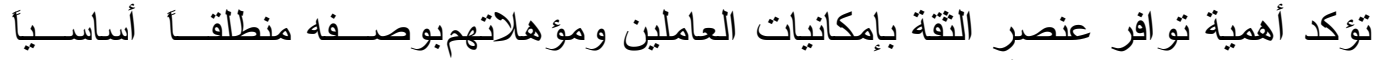

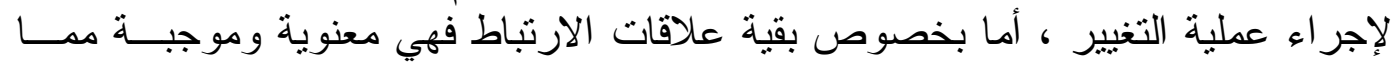
يؤيد سريان فرضية الدراسة الرئيسة الأولى و الفرضيات الفئ الفر عية المنبنقة عنها.

\begin{tabular}{|c|c|c|c|c|c|c|}
\hline \multirow[b]{3}{*}{ المؤشر الكلي } & \multicolumn{5}{|c|}{ 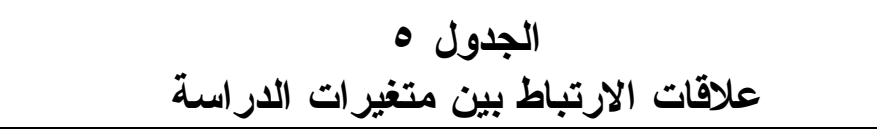 } & \multirow{3}{*}{ المتغير المعتمد المتغير المستقل } \\
\hline & \multicolumn{5}{|c|}{ المداخل الإداريةًة } & \\
\hline & التغييرلة & نشخر ثُقافة & بناء الثقة & المشاركة في & والثقاب & \\
\hline$*_{\cdot, O \Lambda Y}$ & $*_{., O Y V}$ & $*_{\cdot, \xi O Y}$ & $*_{., 091}$ & $*_{., 01 \mathrm{~V}}$ & $*_{\cdot, \varepsilon \uparrow \wedge}$ & مقاومةٌ التغيير \\
\hline
\end{tabular}

\section{ب. تحليل علاقات الأثر بين متغيرات الاراسة}

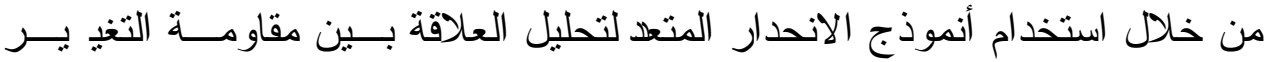

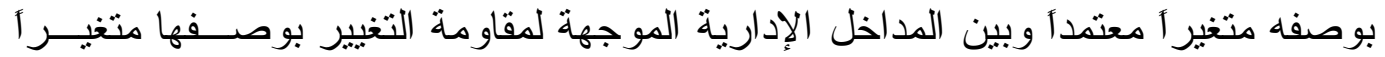

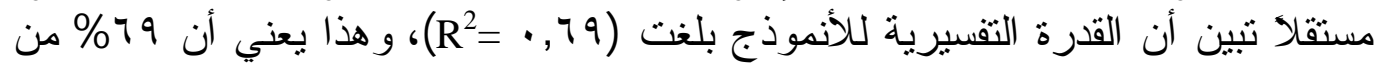

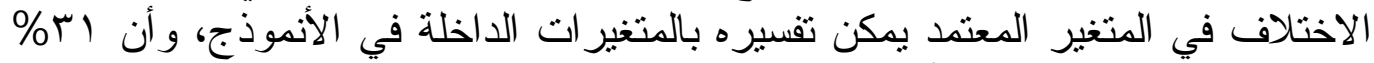
من المتغير ات لم يتضندئها الأنموذج الحالي.

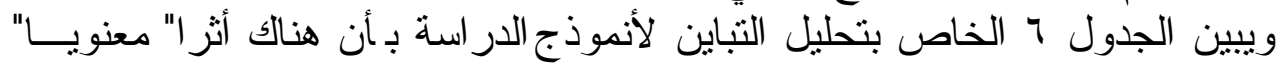

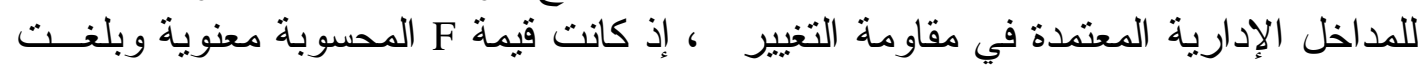

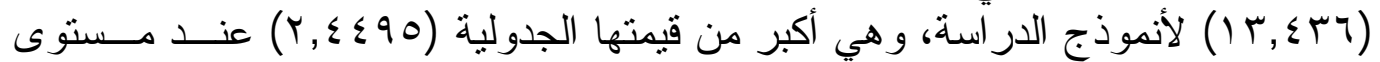

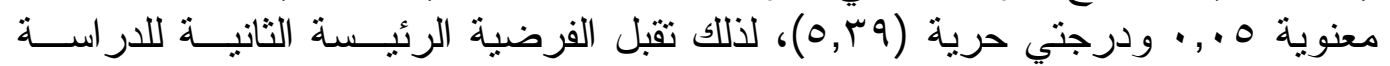

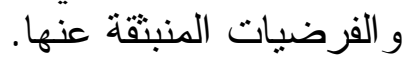

\begin{tabular}{|c|c|c|c|c|c|}
\hline \multicolumn{6}{|c|}{ تحليل التباين لأُموذج الدراسة } \\
\hline & D.F & SS & MS & $\bar{F}$ & Sig \\
\hline Regression & 0 & $\frac{V, Y 07}{Y}$ & $1, \leqslant 01$ & $14,\{\% 4$ & $\cdot, \cdots$ \\
\hline Error & $r 9$ & E,YYY & $\cdot, 1 \cdot \Lambda$ & & \\
\hline Total & $\varepsilon \varepsilon$ & $1, \varepsilon \wedge \lambda$ & & & \\
\hline
\end{tabular}


وبهدف توضيح مساهمات كل عامل من عو امل المتغير المستقل في التــأثنير فــي التهي

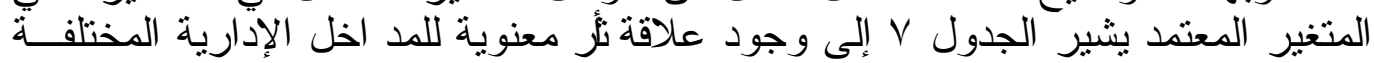
في مقاومة التغيير المغندير

\begin{tabular}{|c|c|c|c|c|c|c|}
\hline \multicolumn{7}{|c|}{ 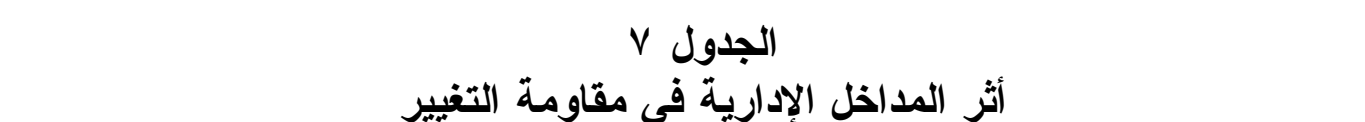 } \\
\hline مدخل جدولة & ثُقافة التغيير نثر & مدخل بناء الثقة & فذخل التشيير & مدخل الثواب & Constant & \\
\hline $\mathrm{B} 5 \cdot, \mathrm{Y} \cdot \varepsilon$ & $\mathrm{B} 4 \cdot, \mathrm{rYq}_{4}$ & $\mathrm{~B} 3 \cdot, \wedge \varepsilon \varepsilon$ & $\mathrm{B} 2 \cdot, \varepsilon 1 \Gamma$ & $\mathrm{B} 1 \cdot, 09 \mathrm{~V}$ & B0 $\cdot, 90$ & Coef B \\
\hline$\cdot, v \backslash 1$ & $.70 \xi$ & $\cdot, \varepsilon Y \Gamma$ & $\cdot, 0 T^{\prime}$ & $\cdot, \leqslant 97$ & $\cdot, \wedge q$. & St.Dev. \\
\hline $1,9.0 *$ & $r, 0 V \cdot *$ & $r, \wedge 9 Y^{*}$ & $r, 17 \gamma^{*}$ & $r, \varepsilon) \leqslant *$ & $0,94 *$ & Cal.T \\
\hline
\end{tabular}

من خلال متابعة معاملات B وقيم اينتين بأن أعلى نسبة تأثير كانت لمدخل نـشـر

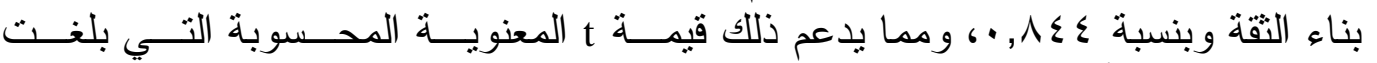

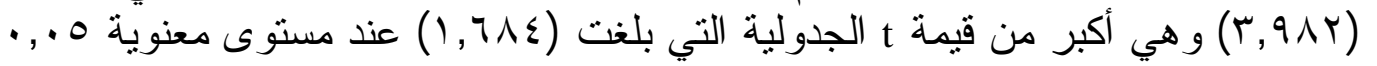

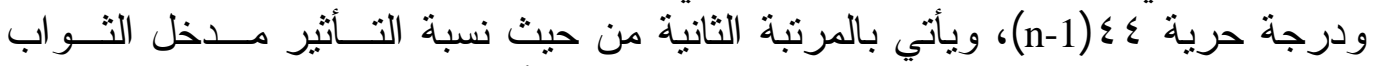

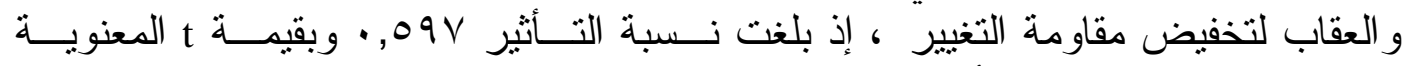

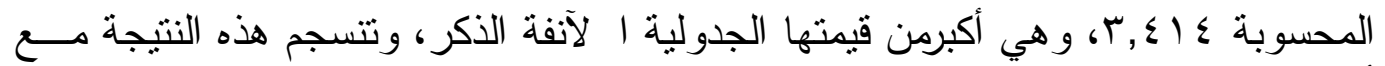

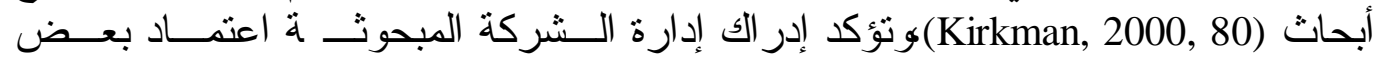

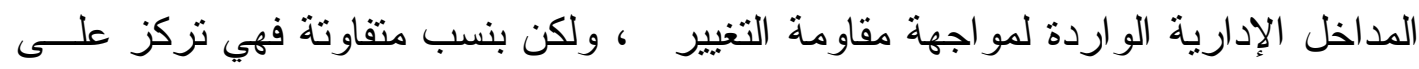

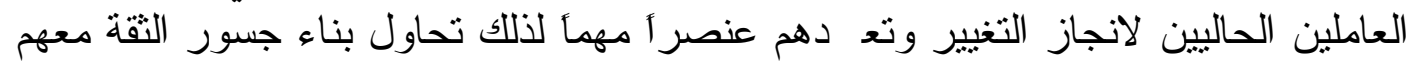

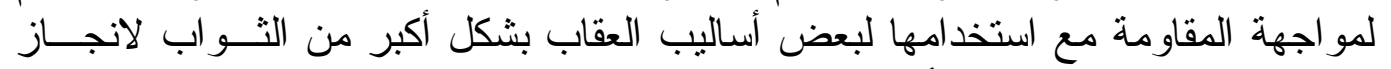
ذللك و هكذا تدريجياً بالنسبة لتأثير بقية المداخل الإدارية.

\section{الاستنتاجات و المقترحات}

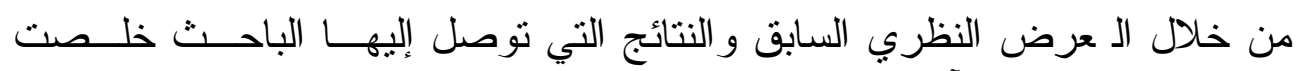
الدر اسة إلى الاستتاجات الآتية:

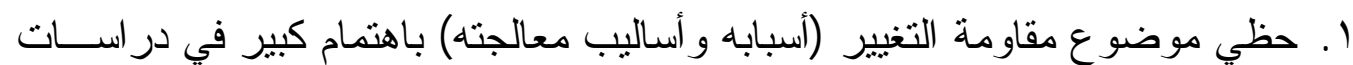

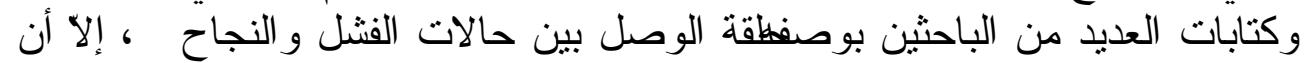

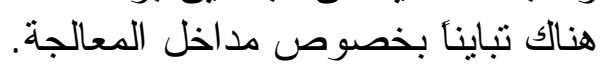

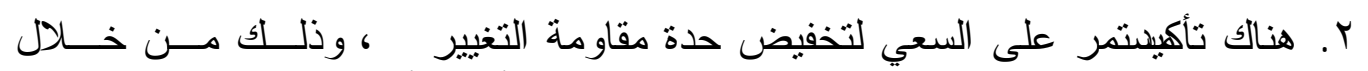

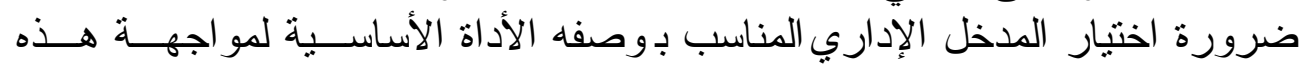
المقاومة و القضاء عليها أو تحويلها بالاتجات التاه الايجابي.

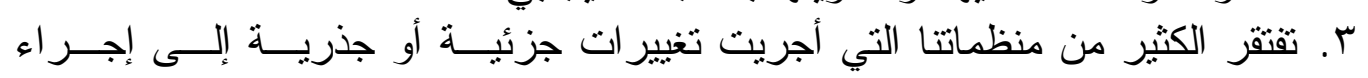

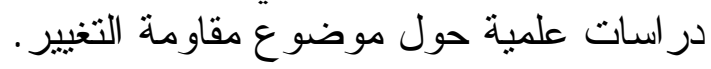




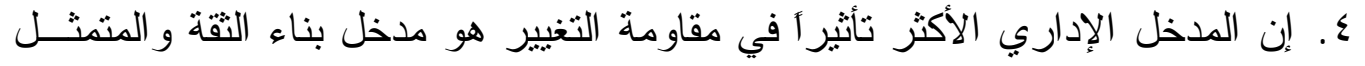

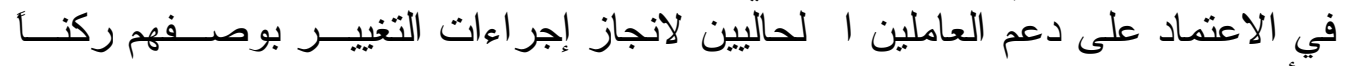

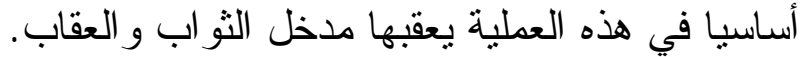

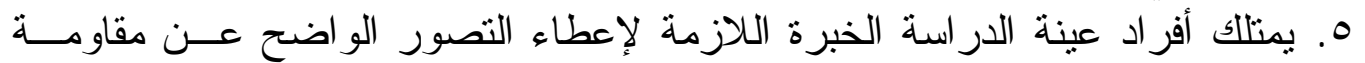
التغيير في الثركة.

هنآك ضعف في اعتماد المداخل الإدارية الأخرى كمدخل نشر ثقافة التغيير ومدخل

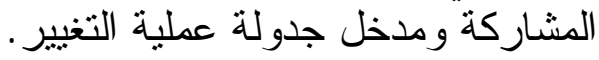

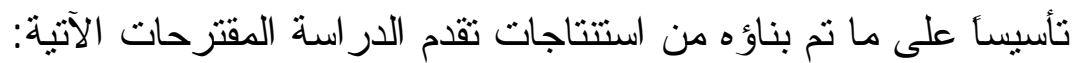

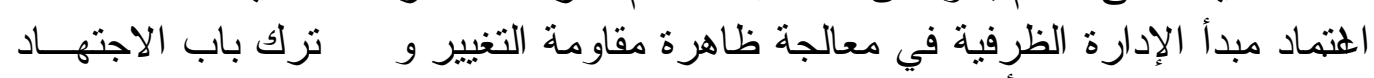

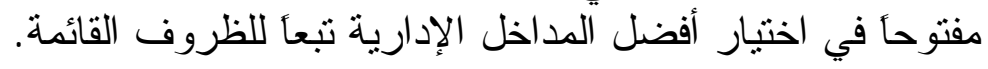

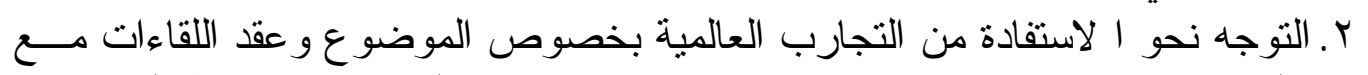

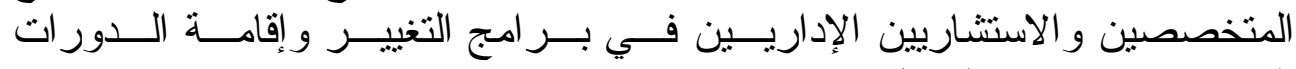
المتخصصة في هذا المجال.

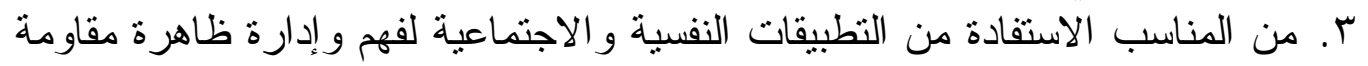

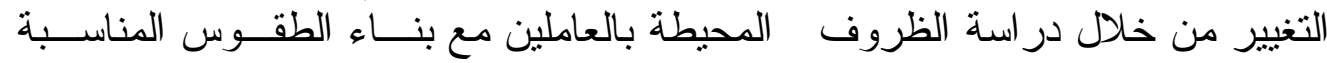
لالتغيير من ع. . بناء تقافة التغيير لاى الأفر ادوتحديد طبيعته و آليات تتفيذه ودفع الأفــر اد للالتــز ام بمبادئه وشروطاه.

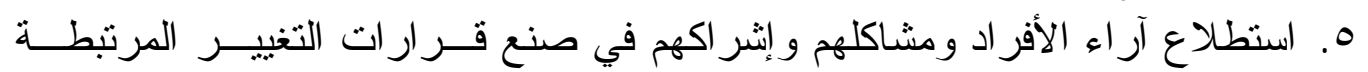
بوحداتهم ووظائفهم.

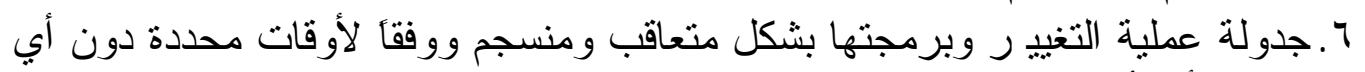
تباطؤ أو تأخير.

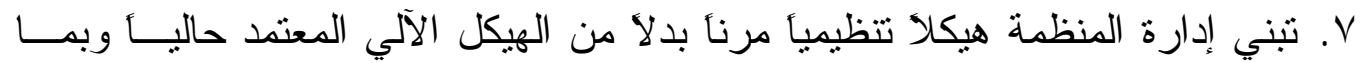

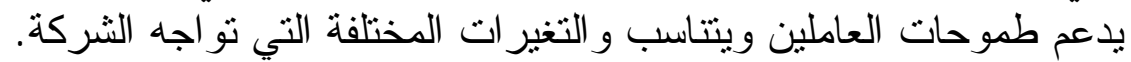

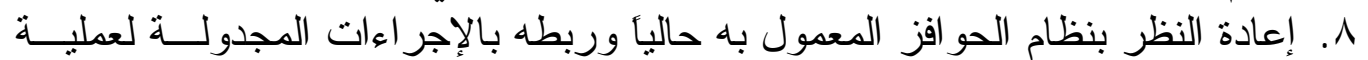
النغيير.

\section{أولاً - المر اجع باللغة العربية}

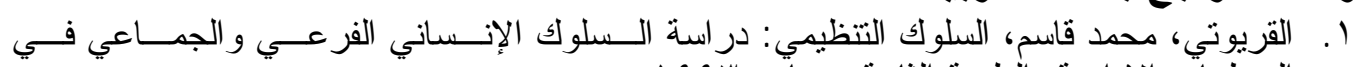

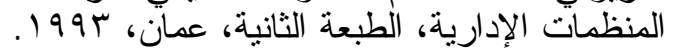

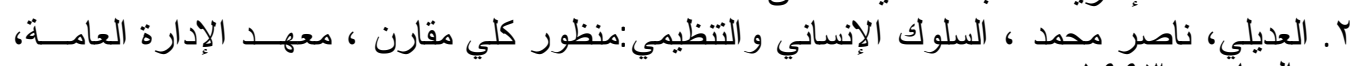

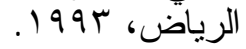

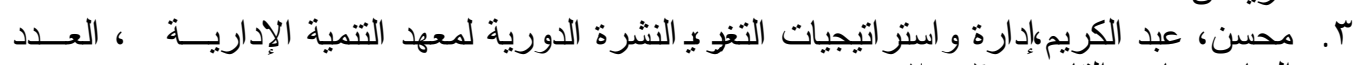

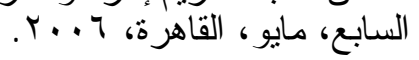




\section{ثاتياً- المراجع باللغة الأجنبية}

1. Ansoff, I. The New Corporate Strategy, John Wiley \& Sons, New York, 1998.

2. Beer, M. \& Eisenstat R. Developing Organization Capable of Implementing Strategy and learning, Human Relation, Vol. 49, No.5, 1996.

3. Coetsee, L. From Resistance to commitment, Public Administration Quarterly, Summer, 1999.

4. Folger, R. \& Sharilick, D. Unfairness and resistance to change: hard ship as mistreatment, Journal of Organizational Change Management, Vol.7, 1999.

5. Ghoshal, S. \& Bartlett, C. Changing the Role of Top Management: Beyond Structure to Processes, H.B.R., Jan-Feb, 1995.

6. Ghoshal, S. \& Barttett, C. Rebuilding Behavioral context: A blue print for corporate Renewal, Sloan Management Review, Vol. 37, No. 2, 1996.

7. Harris, O. \& Jeff, J. Managing People At Work, John- Wiley \& Sons Inc., New York, 1976.

8. Hultman, K. Scaling the wall of Resistance, Training \& Development, Oct, 1995.

9. Jager, D. Resistance to change anew view of an old problem, The futurist, May-Jun, 2001.

10. Kanter, R. Managing the Human Side of Change, Englewood Cliffs, New Jersey, PrenticeHall Book Co, 1995.

11. Kirkman, B. Why do employees resist team? (Examining the resistance Barrier to work), International Journal of conflict Management, Nov, 2000.

12. Maurer, R. Using resistance to build support for change, Journal for Quality and Participation, June, 1996.

13. Milton, C. \& Entre Kin, L., Organization Behavior, Prentice- Hall book Co., Sydney, 1984.

14. Morgan, G. Images of Organization Thousand Oaks, CA Sage Publications Inc, 1997.

15. Nancy, M. \& Robert, T. Managing change: An overview JAMIA Journal, Vol. 7, No.2, Mar:-Apr, 2000.

16. Piderit, S.K. Rethinking resistance and recognizing ambivalence (a multidimensional view of attitudes to ward an organizational change), Academy of Management, Oct, 2000

17. Schaffer, R. \& Thomson, H. Successful Change Programs Begin with Results, H.B.R., JanFeb, 1992.

18. Schalk, R. \& Freese, C. Change and employee behavior, Leadership and Organization Development Journal, Vol. 19, No.3, 1998.

19. Streble, P. Choosing the right change path, California Management Review, Vol. 36, No.2, 1994.

20. Werther, W. \& Keith, D. Personal Management and Human Resources, McGraw-Hill Book Co., Japan, 1982.

21. Whit, D. \& Bendar, D. Organizational Behavior, Allyn \& Bacon Book Co., Boston, 1991.

22. Zander, A. Resistance to change its Analysis \& Prevention (Human Relation in Management), $2^{\text {nd }}$ ed. , South-Western, Pub. Co., New York, 1972. 